\title{
Comparative Cognition and Neuroscience
}

\author{
CHARLES T. SNOWDON AND KATHERINE A. CRONIN
}

Developmental processes are typically viewed from the perspective of an individual's history, but these processes can also be viewed from the broader historical context of evolution by natural selection. The study of the evolution of cognition and its neural correlates involves the use of a comparative method: the study of multiple species that differ in one factor that may influence the selective pressures on the trait of interest. Factors investigated may include phylogeny (e.g., birds vs. mammals, or apes vs. monkeys), social structure or social organization (e.g., multimale, multifemale groups vs. families), mating system (e.g., monogamy vs. polygamy), group size (e.g., pair with offspring vs. many individuals), foraging behavior (e.g., generalist vs. specialist, or clumped vs. distributed food resources), or ranging behavior (e.g., territorial vs. migratory). Thus, someone interested in the evolutionary origins of language might compare the abilities of humans with those of other great apes. Someone interested in spatial memory might compare two closely related species, one that stores food in many locations and recovers the food later and another that does not store food.

The typical view of evolutionary processes is that they diverge. As new species form and become reproductively isolated, they diverge from one another. From this perspective, those species that have shared ancestry and are similar on most variables but differ on some critical one (e.g., monogamous vs. polygamous mating systems in some closely related rodent species) are the comparisons of greatest interest. However, an additional view of evolution is one of convergence (see Figure 3.1). Two quite distantly related species may face similar ecological problems and may independently reach similar solutions. One example is color vision, which has independently appeared in some, but not

We thank Bridget Pieper and Carla Boe-Nesbit for critical comments on the manuscript and Andrew Fox for critical feedback on neural mechanisms of cooperation. Our research was supported by U.S. Public Health Service Grant MH035215 and a Hilldale Professorship from the University of Wisconsin, Madison. KAC was supported by a National Science Foundation Graduate Fellowship. all, insects, fish, birds, and mammals. Presumably, in environmental conditions where color vision would benefit the reproductive success of individuals, individuals possessing mutations leading to color vision would be more likely to survive and would leave more surviving offspring with the color vision mutation. Many cognitive and behavioral phenomena appear as examples of convergent evolution: families as the basic reproductive unit in many birds, marmosets, tamarins, titi monkeys, and humans; enhanced spatial memory in seed-caching birds and rodents; vocal learning in birds, marine mammals, and humans, and so forth.

In this chapter, we first discuss the methods and cautions of comparative studies and then focus on a selection of cognitive phenomena for which there are good comparative data and at least some information on the neural bases. We include social processes among the phenomena that we

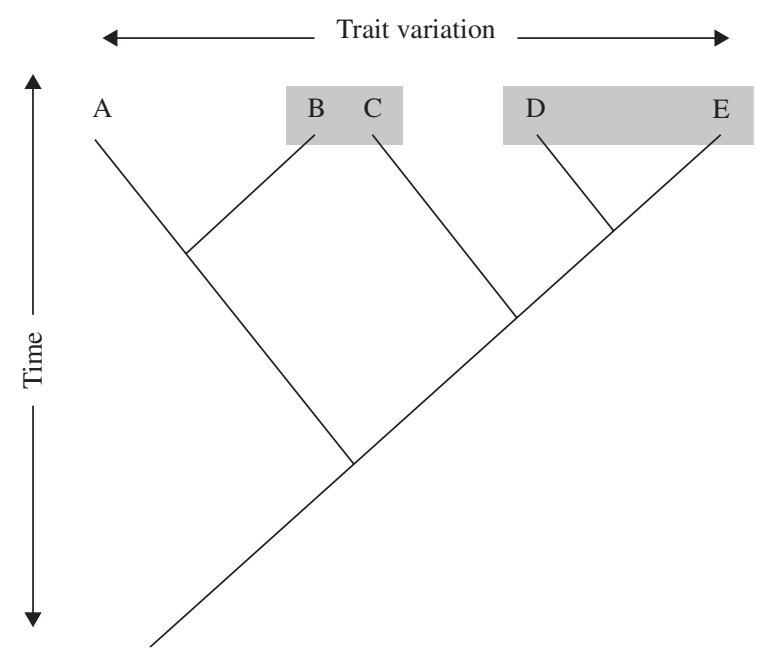

Figure 3.1 Convergent and divergent evolution.

Letters represent species on this hypothetical phylogenetic tree. The less the horizontal distance between species, the more similar the species are on the trait of interest. Species D and species E are more closely related to each other than are species B and species C. However, species D and species E are less similar on the trait of interest and are an example of divergent evolution, whereas species $\mathrm{B}$ and species $\mathrm{C}$ are more similar on the trait of interest and are an example of convergent evolution. 
call cognition. Thus, we review cooperation and prosocial behavior, social learning, spatial memory, and pair bonding. An obvious omission is comparative work on bird song learning and its neural mechanisms, which is covered in Chapter 45.

\section{METHODS AND CAUTIONS}

\section{Choosing Species for Comparison}

The selection of appropriate species for comparison depends on the nature of the question being addressed. However, often species are chosen on the basis of phylogenetic similarity alone. For example, chimpanzees (Pan troglodytes) and bonobos (Pan paniscus) are the closest relatives of humans, but these apes diverged from humans more than 4.5 million years ago. Behaviorally, chimpanzees differ significantly from bonobos by being more competitive and aggressive, and both species differ from humans in significant ways. Nonetheless, because both species have relatively large brains that are similar in form to those of humans, these species may be good models for comparisons with humans involving some cognitive abilities. However, they may not be good models for comparisons with some human social and emotional processes because the social environments of these species differ greatly from our own.

Comparative models might also be chosen from species that are quite different but share some interesting commonality. For example, human fathers often appear to display competence in caring for and bonding with their infants, something rarely, if ever, observed in other great apes. However, fathers in several New World primate species and in some rodents and many birds exhibit spontaneous care of infants and form long-lasting bonds, making these species potentially better candidates than great apes and Old World primates for studying paternal behavior (Snowdon $\&$ Ziegler, 2007). As we show here, species with extensive coordination of infant care between different group members are more likely to exhibit social learning (Coussi-Korbel \& Fragaszy, 1995) and cooperative behavior (Cronin, Kurian, \& Snowdon, 2005). Ecological factors affecting foraging behavior can also lead to differences in rapidity of social learning (Lefebvre \& Palameta, 1988). As we also show, social factors or mating systems can lead closely related species, such as monogamous versus polygynous mice and voles, to have very different behavior, hormones, and neural organizations than we would predict from phylogeny alone.

Important comparisons may also be made within species. Call and Tomasello (1996) and Thompson, Oden, and Boysen (1997) have shown differences in performance on social learning and second-order analogical reasoning tasks between so-called enculturated chimpanzees that have had extensive human interactions during development compared with chimpanzees that have been reared naturally by their own species. It is not clear what aspects of enculturation are important for high-level cognitive function, but the ability to interact comfortably with the humans who are testing the animals may lead these chimps to exhibit better performance than those with less of a history of interaction with humans. Differences within a single species can also inform researchers of developmental influences on cognition. Seasonal differences may also produce behavioral and neural variation within a species or even an individual. Male birds sing under the influence of testosterone stimulated by increasing day length. Furthermore, changes in the size and neural complexity of brain areas track seasonal differences, with consequent changes in rates of singing or song structure and complexity (Alger \& Riters, 2006; Nottebohm, 1981; G. T. Smith, Brenowitz, Beecher, \& Wingfield, 1997; see Chapter 4 for more details).

\section{No Scala Naturae}

Hodos and Campbell (1969) argued against the concept of scala naturae, a popular misconception that behavioral changes follow a natural phylogenetic scale from earlier evolved species exhibiting simpler behavior to more complex and more recently evolved species necessarily exhibiting more complex behavior. You still can find psychology texts talking about invertebrates having less complex behavior than fish, which in turn are simpler than birds, which are simpler than mammals. The reality of evolution is much messier than a simple linear hierarchy implies. Honeybees have a complex communication system to indicate the location of nectar (Von Frisch, 1950). Salmon remember the odors of their home streams over several years of ocean living and can return to their natal streams to spawn (Hasler, 1966). Clark's nutcrackers (Nucifraga columbiana) of the U.S. Southwest can store up to 30,000 seeds each fall and can remember the location of enough of these seeds to survive the winter (Balda \& Kamil, 1992). Cotton-top tamarins (Saguinus oedipus; Cronin \& Snowdon, 2008; Hauser, Chen, Chen, \& Chuang, 2003) and common marmosets (Callithrix jacchus; Burkart, Fehr, Efferson, \& van Schaik, 2007) spontaneously display cooperative and reciprocal behaviors that a human parent would admire in his or her children, yet chimpanzees display little evidence of similar positive social behavior (Jensen, Hare, Call, \& Tomasello, 2006; Silk et al., 2005; Vonk et al., 2008; see following discussion).

Vonk and Povinelli (2006) argued that evolution creates no presumption about the phylogenetic distribution of psychological systems among closely related species, and yet, even among presumably sophisticated primatologists who might be expected to have a more subtle appreciation of the processes of evolution, we often encounter the idea that 
primates are somehow more special than other mammals and that apes have cognitive skills surpassing all others. This leads to the frequent dismissal of nonprimate species with complex social structures such as hyenas, wolves, and other social carnivores as well as species more difficult to study, such as marine mammals. In these species one can find evidence of group-specific differences in communication and behavior that might be called culture if seen in apes, as well as coordination of complex social behavior, such as teaching in meerkats (Thornton \& McAuliffe, 2006) and communal hunting in hyenas (Drea \& Frank, 2003).

There is often evidence of clear relationships between aspects of body size, brain size, and cognition. The patterns of allometric relationships may often illuminate interesting exceptions from a strict phylogenetic progression. For example, Figure 3.2 plots body size and encephalization quotient (EQ) for several primate species grouped by phylogeny. There is little variation across New World monkeys, Old World monkeys, apes, and extinct hominoids in brain size as a proportion of body size. However, the two genera with the highest EQs are squirrel monkeys and capuchin monkeys, both New World primates, and one of the genera with the lowest EQ is the gorilla. Note also that modern humans have a significantly greater EQ than any other primate species.

A modern reincarnation of the scala naturae is research that uses allometry of brain size to explain the evolution of language. Dunbar (reviewed in Dunbar, 2003) has shown that among terrestrial Old World primates there is a correlation between group size and neocortex size. This suggests that the cognitive demands of social complexity were driving forces in the evolution of brain size (the social brain hypothesis). Dunbar's measure of social complexity was the number of grooming relationships that are possible within a group, as grooming is an essential component of maintaining social relationships in many primates. As group size increases linearly, the number of potential dyadic and higher order relationships increases exponentially. According to Dunbar, typical human groups average 150 in a social cohort, too large to allow individual relationships to be maintained by grooming. Thus, humans have evolved language, using gossip as a proxy for social grooming. In fact, there does appear to be a relationship between typical group size and neocortex volume among the species selected.

But is the description of the relationship between group size, social complexity, and brain size adequate? Figure 3.3A shows New World primates that diverged from the ape lineage earlier than Old World monkeys. The monkeys with the largest brains and the largest groups (muriquis, Brachyteles spp.) almost never groom one another (Strier, 1997), whereas the primates with brains with less neocortical volume and the smallest group sizes (marmosets and tamarins) groom extensively. One field study of common marmosets reported adult pairs grooming each other more than $20 \%$ of the day (Lazaro-Perea, de Fatima Arruda, \& Snowdon, 2004). Figure 3.3B shows that for both New World primates and apes there is a linear relationship between EQ and group size; so the basic relationship between group size and brain size still holds, but not for grooming time. These findings argue against a clear relationship between group size, grooming, social complexity, and the evolution of the neocortex. One lesson from this is that limiting the selection and range of species studied can potentially lead to different conclusions. Another lesson is that brain size is not necessarily

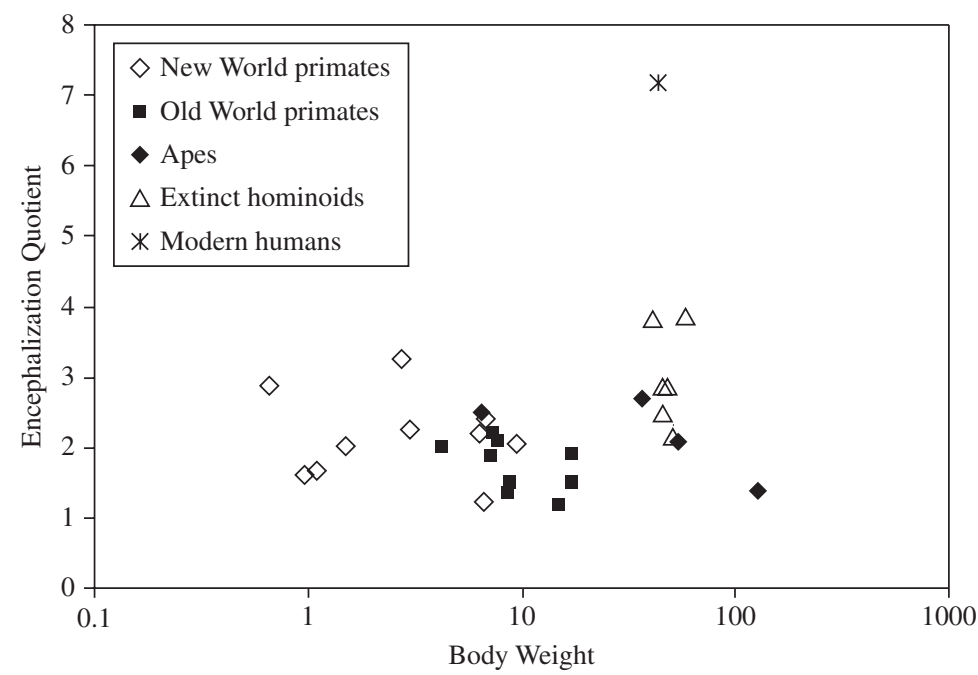

Figure 3.2 Encephalization quotient (EQ) plotted against log body weight for several genera of primates.

Note the variation within each group of primates (Saimiri and Cebus as New World primates have higher EQ's than all other nonhuman primates. Gorillas, furthest to the right, have a small EQ relative to all great apes and most monkeys. Only modern humans have an EQ that is not in the range of other species. (Drawn from data in Aiello \& Dean, 1990) 

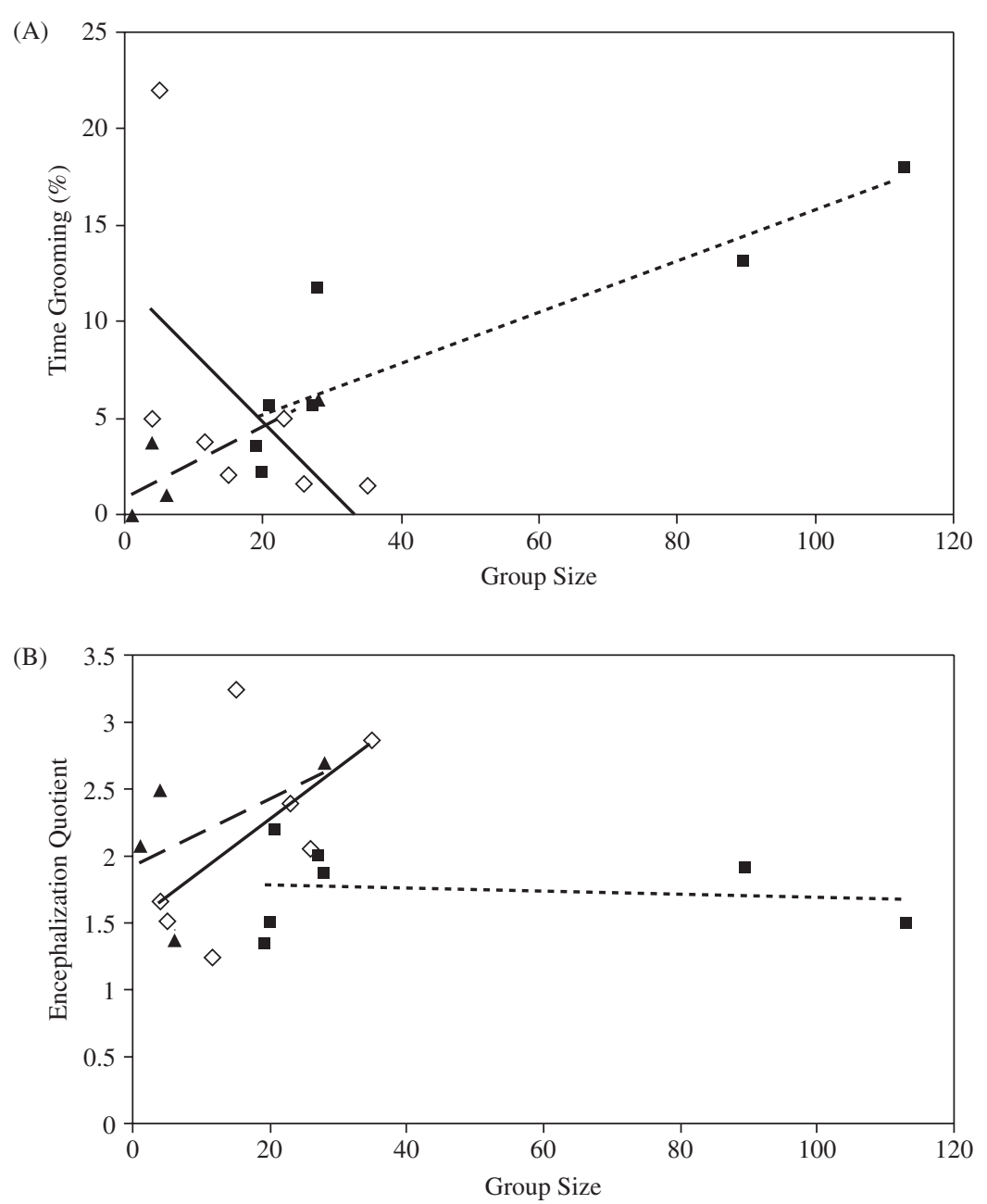

Figure 3.3 The linear regression from New World primates is shown by a solid line, for Old World primates by a dotted line and for Apes by a dashed line.

A. Grooming time as a function of group size in selected genera of New World primates, Old World primates and apes. Regression lines for Old World primates and apes have a positive slope, whereas New World primates show a negative relationship between grooming time and group size. (Data from Dunbar, 1991)

B. Encephalization quotient as a function of group size in the same genera showing a positive relationship between brain size and group size for New world primates and apes and no clear trend for Old World primates. EQ data from Aiello and Dean (1990) and group size data from Dunbar (1991). synonymous with complexity. As a nonprimate corollary of this, G. T. Smith et al. (1997) found that although the sizes of brain areas related to song production changed with the seasons in song sparrows, some of the change was due to changes in average neuron size and neuron density rather than in the number of neurons. Complexity must be carefully defined, and we should not assume that differences in size must necessarily be related to differences in complexity.

\section{Anthropomorphism and Anthropocentrism}

Many of the problems with the scala naturae view among scientists otherwise quite sophisticated about natural selection and evolution may be due to both anthropomorphism (ascribing human traits to nonhuman animals) and anthropocentrism (seeing cognition in other species through the lens of human abilities). When species are more similar to humans, it may be difficult to avoid ascribing humanlike cognition to these species. Even when we try hard to avoid being anthropomorphic, it is nearly impossible to avoid being anthropocentric. This has led to the idea that increasingly complex social life (as measured by mean group size) must be accompanied by increasingly complex cognitive and social skills (Barrett, Henzi, \& Rendall, 2007). As mentioned, social group size may not be a good index of brain complexity, and many species far removed from humans have displayed complex cognition on one or more dimensions in the context of their environment. Furthermore, it may be a mistake to assume that all of human behavior is governed by complex cognitive processes. Many of us engage in automatic behaviors (routines in cooking, driving to work, semantically meaningless phrases used in greetings, etc.). We may be overrating our own cognitive ability simply because we are the species doing the rating. Cognitive complexity must be seen through the lens of the species being studied. None of this is to deny the very real abilities of humans but instead to urge scientists to be more modest when evaluating human abilities (and those of other great apes) compared with those of other species. 


\section{Problem of Plasticity}

Comparing species on different aspects of cognition is one way to gain a deeper understanding of cognitive processes and cognitive evolution, yet animals, human and nonhuman, are notoriously plastic and are able to modify behavior. For example, ecological differences between captive and wild environments may lead to different behavior within the same species. Leavens, Hopkins, and Bard (2005) have shown that pointing behavior is observed readily in captive chimpanzees interacting with humans to obtain food, whereas pointing has never been observed in the wild. Unlike wild tamarins, captive-born cotton-top tamarins do not exhibit fear when exposed to snakes, a natural predator (Campbell \& Snowdon, in press; Hayes \& Snowdon, 1990). Captive-born tamarins responded with equal arousal to playbacks of calls of some natural predators and vegetarian howler monkeys, suggesting that initial responses to predator calls may be flexible and may be related to certain acoustic properties rather than innate predator recognition (Friant, Campbell, \& Snowdon, 2008). Captive tamarins spontaneously produced alarm calls when fed a familiar food that had been adulterated with pepper, although they had never alarm called at that food previously (Snowdon \& Boe, 2003). They also gave mobbing vocalizations toward a caretaker acting as though coming to catch a monkey, despite their lack of arousal toward natural predators (Campbell \& Snowdon, 2007). These results on captive chimpanzees and tamarins suggest that captivity represents an ecological niche to which animals may adapt, leading to changes in behavioral contexts different from those in which their wild conspecifics would show similar behavior. Withinspecies comparisons of individuals living under different social or environmental conditions can identify the environmental (as opposed to phylogenetic and genetic) variables that can affect cognitive processing and behavioral expression.

This contextual flexibility may paradoxically utilize simpler neural processes than those hypothesized for contextually inflexible cognitive processes. For example, with respect to communication between animals, Owren and Rendall (1997) have argued for flexibility in the contexts in which signals are used and how they are responded to by others. They offered a simple model of affective conditioning by which individuals learn the relationships between signals and affective state. As environments change, organisms can acquire new signal-meaning correspondences. Saffran, Aslin, and Newport (with human infants; 1996) and Hauser, Newport, and Aslin (with cotton-top tamarins; 2001) have demonstrated that human babies and monkeys can learn about statistical regularities in auditory input, a simple but rapid way in which organisms can acquire contingencies between sounds. Thus, an animal in a novel context (e.g., captivity) can quickly learn to associate alarm calls with caretakers or veterinarians rather than leopards and snakes, or can learn to eat foods different from those found in the wild and still give appropriate food calls. These basic processes of conditioning provide a general way to learn rapidly about associations of signals and events in the environment without reliance on a host of hypothetical modality and context-specific modules that have been shaped by evolution (Tooby \& Cosmides, 1990). Successful adaptation is more likely to occur when organisms can respond rapidly to changes in environment than rely on hard-wired species-specific stimulus-response connections.

Two striking examples of plasticity come from work on rodents. For the first, Marler and colleagues studied two species of mice (Table 3.1). The California mouse (Peromyscus californicus) is one of the few species known from field studies to be both socially and genetically monogamous (Ribble, 1991). Males defend their mates and play an important role in infant care, with infant survival being affected by fathers (Gubernick \& Tefari, 2000). The white-footed mouse ( $P$. leucopus) is a close relative but is polygamous. These mice do not form pair bonds, and individual males and females may mate with many others. Males provide little, if any, infant care and do not show territorial defense. Bester-Meredith and Marler (2001) successfully cross-fostered these mice and showed that California mice reared by white-footed mice exhibited reduced paternal care and reduced territorial defense behavior, becoming more similar to their foster species. Furthermore, the patterns of distribution of vasopressin (a neuropeptide hormone related to aggression) staining in the brains of cross-fostered California mice more closely approximated the distribution patterns seen in white-footed mice than those seen in their own species. Within California mice, sires that were retrieved less as young retrieved their pups less often when they became adults (Bester-Meredith \& Marler, 2001). An experimental increase in the amount of retrievals experienced by California mice offspring led to decreased attack latencies in both males and females and greater vasopressin immunoreactivity in the dorsal bed nucleus of the stria terminalis (Frazier, Trainor, Cravens, Whitney, \& Marler, 2006). Cross-fostering (CF) to another species can change not only behavior but also brain organization and brain function. The specific nature of the crossfostering experience that leads to behavioral and neural changes is fairly minimal.

In the second example, the work of Meaney and collaborators has shown that variations in maternal licking and 
TABLE 3.1 Effects of cross-fostering (CF) on behavior and arginine vasopressin (AVP) brain staining in mice.

\begin{tabular}{lllll}
\hline $\begin{array}{l}\text { Species } \\
\text { Cross- } \\
\text { Fostered }\end{array}$ & $\begin{array}{l}\text { Territorial } \\
\text { Aggression }\end{array}$ & $\begin{array}{l}\text { Neutral } \\
\text { Arena } \\
\text { Aggression }\end{array}$ & $\begin{array}{l}\text { Paternal } \\
\text { Care }\end{array}$ & $\begin{array}{l}\text { AVP- } \\
\text { Immuno } \\
\text { Staining }\end{array}$ \\
\hline $\begin{array}{l}\text { White- } \\
\text { footed } \\
\text { mouse }\end{array}$ & No effect & Control $<$ CF & No effect & No effect \\
$\begin{array}{l}\text { California } \\
\text { mouse }\end{array}$ & Control $>$ CF & No effect & Control $>$ & Control $>$ \\
\end{tabular}

Note. From "Paternal Behavior and Aggression: Endocrine Mechanisms and Non-Genomic Transmission of Behavior," by C. A. Marler,

J. K. Bester-Meredith, and B. C. Trainor, 2003, Advances in the Study

of Behavior, 32, pp. 263-323. Adapted with permission. Elsevier Science 2003

grooming in rats (Rattus norvegicus) are related to variations in stress reactivity, with greater amounts of licking and grooming reducing stress reactivity of the pups when they are adults. Furthermore, when offspring become adults they show similar licking and grooming patterns as their mothers. Cross-fostering studies showed these effects to be nongenomic but purely a result of the early grooming and licking received (Francis, Diorio, Liu, \& Meaney, 1999). High levels of maternal licking and grooming translated into differences in hippocampal glucocorticoid receptor messenger RNA expression (Liu et al., 1997) as well as increased synapse formation in the hippocampus, increased expression of N-methyl-D-aspartic acid receptors, increased cholinergic innervation of the hippocampus, and enhanced spatial learning and memory (Liu, Diorio, Day, Francis, \& Meaney, 2000). Furthermore, high levels of early maternal care are associated with differences in responsiveness of oxytocin receptors to stimulation by estrogen (Champagne, Diorio, Sharma, \& Meaney, 2001).

That such small but significant differences in early rearing can have profound effects on behavior and brain function in several species should caution us about thinking about behavior as being determined solely by the direct effects of natural selection. Organisms are not static entities but respond flexibly and dynamically to their environments.

\section{SOCIAL LEARNING}

Social learning (or socially mediated learning) has been studied in a wide range of species. Social learning occurs when the acquisition of behavior is influenced by the activities of other individuals, either directly or indirectly (Box, 1984). Much research has focused on the mechanisms that enable social learning, such as an observer's attention being drawn to a particular object as a result of another individual interacting with that object (stimulus enhancement;
Spence, 1937), or the increased likelihood of performing a familiar motor action after seeing it performed by another individual (response facilitation; Byrne, 1994). More than seven mechanisms that enable social learning have been identified (Whiten \& Ham, 1992).

One mechanism, imitation, has received the most attention and has been categorized as the most challenging and unique form of social learning (Byrne, 1999). Some have argued that imitation requires theory of mind, or the ability to conceive of the intentions of others (Premack \& Woodruff, 1978; see also Stone, this volume). Because theory of mind is widely thought to be an ability restricted to humans and potentially other great apes (Byrne, 1999), it has been argued that imitation is impossible for other taxa (Whiten \& Ham, 1992). Miklosi (1999) reported that although some studies have provided data in support of imitative abilities in other species, others have quickly criticized and reinterpreted the results. The prevalence of imitative ability across taxa, and the cognitive mechanisms that underlie imitation, will likely be a hotly debated issue for some time, especially because some researchers with beliefs in scala naturae will cling to the uniqueness of imitation for humans and great apes.

In order to evaluate the social learning capability or tendency of a group or species, researchers typically employ one of three methodologies. The first is simply exposing an individual trained to perform a skill to one or more naive individuals and then measuring whether the skill is expressed by the formerly naive individual(s). The second, transmission or diffusion chains, uses the same idea but measures whether the formerly naive individual subsequently transfers the acquired behavior to another naive individual (e.g., Galef \& Allen, 1995). The third is the dual action task, in which there are two functionally equivalent methods available for solving a task. Individuals observe one or the other method and then are tested on whether their performance matches the method employed by the demonstrator (e.g., Humle \& Snowdon, 2008).

Social learning can permit behavioral calibration to the unpredictable properties of an environment with a degree of specificity not permitted by genetically coded information (Galef \& Laland, 2005). However, it is a common misconception to assume that social learning is always more advantageous than individual learning, and indiscriminate copying of surrounding individuals is unlikely to be a stable strategy in all species (Boyd \& Richerson, 1988; Laland, 2004). Theoretical models have demonstrated that social learning is more effective than individual learning when two conditions are met: (1) the cost of individually acquiring accurate information is high, and (2) knowledgeable individuals are present that have experienced the same environment (Boyd \& Richerson, 1988). Therefore, 
we would expect that even closely related species might display different propensities to acquire information socially if they have evolved in different environments. Laland has expanded on these models to argue that natural selection should have favored heuristics dictating when individuals should acquire information socially, and from whom the information should be obtained.

Decades ago, Klopfer $(1959,1961)$ proposed two hypotheses to account for interspecific variation in social learning. He reasoned that solitary species should demonstrate less social learning than gregarious species, and species with conservative foraging strategies should exhibit less social learning than species with opportunistic foraging styles. In fact, most attempts to predict or explain interspecific differences in social learning to date have been based on differences in either sociality or feeding ecology.

\section{Influence of Sociality on Social Learning}

Coussi-Korbel and Fragaszy (1995) presented a model relating social learning to social organization. They argued that behavioral coordination in time and/or space is common to all forms of social learning and that the extent to which behavioral coordination is expressed predicts social learning. An example of behavioral coordination in time (but not space) is a flock of birds feeding simultaneously while the nearest neighbors are at some distance. An example of behavioral coordination in space (but not time) is when an individual approaches a location where a conspecific was previously active but is no longer present. It is only behavioral coordination in both time and space that requires physical proximity between individuals. Differences in the amount of spatial proximity sought out and tolerated by conspecifics vary greatly across species and can often be related to larger social constructs such as dominance structures or mating systems. In despotic species, proximity between conspecifics, particularly near food or desirable items, will be infrequent. In more egalitarian species, however, proximity between conspecifics will be more common. Therefore, the social context in which an individual is immersed is likely to influence opportunities for, and subsequent expression of, social learning.

However, it is not always the case that hierarchically organized species demonstrate less social learning. It appears that when the social hierarchy promotes close, constant monitoring of other individuals and their behavior, the probability for social learning may increase because of the increased attention paid to conspecifics. When the attention structure brought about by the hierarchy promotes social learning, it should do so in a heterogeneous fashion (Coussi-Korbel \& Fragaszy, 1995). That is, not all individuals will acquire the socially learned behavior, but rather those that are positioned relatively lower within the hierarchy will be more likely to attend to a demonstrator that is relatively more highly ranked and to subsequently express the modeled behavior.

Some studies have made explicit attempts to relate social organization to social learning by performing interspecific comparisons of phylogenetically similar species. Cambefort (1981) compared the discovery and propagation of a feeding skill in chacma baboons (Papio ursinus) and vervet monkeys (Cercopithecus aethiops). The results were also compared with those of a previous study of mandrills (Mandrilli sphinx; Jouventin, Pasteur, \& Cambefort, 1976). These three primate species belong to the same family, Cercopithecidae (Nowak, 1999), but exhibit different social organizations. The propagation of the socially learned feeding skill was closely related to the social structure or, more specifically, the attention structure of each species. Vervet monkeys exhibited the weakest hierarchy and group cohesion, and there was no social transmission of the novel foraging skill. In chacma baboons, which exhibited intermediate hierarchy strength, group cohesion, and attention to social partners, there was weak transmission of the novel foraging skill. Finally, in mandrills, which demonstrated the strongest hierarchy, strongest group cohesion, and most attention to social partners, there was fast social propagation of the novel foraging skill. Therefore, the pattern of transmission of the novel behavior mapped onto the hierarchical organization of the group.

Another study compared the social transmission of flavor preferences in two hamster species-the golden hamster (Mesocricetus auratus), which is solitary, and the dwarf hamster (Phodopus campbelli), which is moderately social (Lupfer, Frieman, \& Coonfield, 2003). When given a choice between a flavor chosen by a demonstrator and another flavor, dwarf hamsters preferred the demonstrator's flavor, whereas golden hamsters preferred the demonstrator's flavor only if the demonstrator was their mother. In the wild, adult dwarf hamsters interact with one another to share burrows and raise pups. In contrast, golden hamsters rarely interact with one another outside of the mother-pup relationship. Therefore, the degree of social learning expressed may have been predicted by the social organization of the species. A similar finding was reported when the more social pinyon jay (Gymnorhinus cyanocephalus) was compared to the less social Clark's nutcracker. The individual and social learning abilities of the two species were compared, and the results indicated that pinyon jays learned faster socially than they did individually, whereas the nutcrackers' performance was not enhanced in the social learning condition (Templeton, Kamil, \& Balda, 1999). 
Whereas interspecies comparisons provide insights about the effect of the social organization of a species on social learning, intraspecies comparisons allow for investigation of the effects of social relationships within a species on social learning. Nicol and Pope (1994) found that the social transmission of a behavior (keypecking) in flocks of laying hens (Gallus gallus) was influenced by the hierarchy of the group and that social learning was greatest when the demonstrator was a dominant individual. A similar effect of social relationships was found in a study of cooperatively breeding common marmosets. Dyads were presented with a task requiring both individuals to act, whereby one manipulated an apparatus to bring food into the reach of the second individual, who could then retrieve the food. Dyads in which the more dominant individual assumed the role of retriever were more successful at solving the coproduction task. However, in the successful dyads, dominant individuals did not consume more rewards than subordinates, even though they had more direct access to the food rewards (Werdenich \& Huber, 2002).

Schwab, Bugnyar, Schloegl, and Kotrschal (2008) demonstrated that affiliative relationships among kin enhanced the performance of common ravens (Corvus corax) in a social learning task. Drea and Wallen (1999) reported intriguing results indicating that subordinate rhesus macaques (Macaca mulatta) performed less well on learning tasks when in the presence of dominant individuals, even though they had learned the information equally well. Drea and Wallen (1999) were not investigating social learning specifically, but their findings, combined with those of other studies on the effects of social relationships on performance, indicate that the identity of the demonstrator, as well as by-standers in the experimental setup, likely influences the degree of social learning expressed.

Intraspecies comparisons can also elucidate developmental differences in social learning. Dependence on social learning may vary in predictable ways throughout the lifetime of an individual (Galef \& Laland, 2005). As mentioned previously, there are likely fewer opportunities for social learning in a species that is rarely in proximity with conspecifics, but during periods of offspring dependence proximity will be more frequent and social learning opportunities may be quite regular. Black rats (Rattus rattus) learn socially to open pinecones to obtain seeds; however, it is only the pups, not adults, that are able to acquire the technique by observing experienced rats (Aisner \& Terkel, 1992). Across many studies and species, it seems that juveniles are more likely than adults to incorporate new actions into their behavioral repertoire (e.g., Goodall, 1986; InoueNakamura \& Matsuzawa, 1997; Kawai, 1965).

Chimpanzees are generally adept at social learning both in the wild (reviewed in Matsuzawa, 2001) and in captivity (reviewed in Whiten, Horner, \& Litchfield, 2004). Chimpanzee societies exhibit a strict dominance hierarchy, with the most tolerant and longest lasting relationships existing between mother and offspring. An intraspecific comparison of tool use acquisition by young chimpanzees in Gombe National Park, Tanzania, indicated a striking sex difference in the social acquisition of the skill. Females began using tools for termite fishing at a younger age than males, although there was no difference in the behavior of the mother (the model) toward males and females. Young females spent more time watching their mothers use the tools, whereas males spent more time playing at the termite mound. Therefore, the attention paid by the juveniles was an influential factor in determining the onset of the socially learned skill (Lonsdorf, Eberly, \& Pusey, 2004). Again, the direction of attention and the close social relationship appears crucial for predicting the occurrence of social learning.

\section{Influence of Feeding Ecology on Social Learning}

Predictions about the prevalence of social learning across species have also been made on the basis of feeding ecology. Specifically, species with opportunistic or generalist lifestyles, in which individuals are exposed to more environmental variation, should be more likely to demonstrate social learning than species that are conservative or specialists (Johnston, 1982; Klopfer, 1961). This hypothesis rests on the reasoning that social learning allows an individual to modify its behavior to the current environment more efficiently or quickly than would be possible by either individual learning or genetically determined behavior. In this sense, social learning is an adaptive specialization shaped by natural selection.

The influence of feeding ecology on social learning has been explored experimentally. Klopfer (1961) demonstrated that greenfinches (Chloris chloris) learned a food discrimination task less well in pairs than individually, as opposed to great tits (Parus major), which did not suffer a learning decrement in pairs. He speculated that a failure to learn socially about novel foods would only fail to be maladaptive in species that display conservative feeding habits, such as the great tit. Dolman, Templeton, and Lefebvre (1996) compared two populations of Barbados Zenaida doves (Zenaida aurita) with different foraging styles. One population consistently exhibits conspecific aggression while foraging, whereas the other forages in flocks without aggression. The aggressively foraging species performed better on a social learning task that employed a heterospecific demonstrator, whereas the nonaggressive species performed better with a conspecific demonstrator. In this study, the type of feeding environment appeared to predict 
the pattern of social learning expressed, as the population that typically interferes with conspecifics to compete for food was unable to acquire a socially learned skill from a conspecific.

The prevalence of social learning throughout the animal kingdom seems to be best explained by a combination of social, developmental, and ecological factors. Phylogenetic predictions alone appear to do a relatively poor job of explaining interspecific variation in social learning, especially if one considers that comparisons across populations of a single species often lead to as much variation as between-species comparisons.

\section{Social Learning and the Brain}

It is unlikely that the neuronal bases that underlie social learning differ dramatically from mechanisms known to underlie other forms of learning (for a review of the neuronal basis of learning, see Chapter 26).

However, an additional pattern of neuronal activation may be unique to social learning and may not be involved in asocial learning such as classical or operant conditioning or trial-and-error learning. Mirror neurons have been identified in macaques (Macaca ssp.) in the ventral premotor and rostral inferior parietal cortex (see Figure 8.11 in Chapter 8 for the approximate location). The defining characteristic of mirror neurons is that they fire both when the animal performs an object-oriented action with its hand or mouth, and when the animal observes another individual (human or conspecific) performing the same motor action (di Pellegrino, Fadiga, Fogassi, Gallese, \& Rizzolatti, 1992; Gallese, Fadiga, Fogassi, \& Rizzolatti, 1996; Rizzolatti, Fadiga, Gallese, \& Fogassi, 1996).

A leading hypothesis regarding the function of the mirror neuron system posits that mirror neurons are the basis of action understanding (Rizzolatti, Fogassi, \& Gallese, 2001). Indeed, accumulating evidence suggests that the understanding of the meaning of actions determines the discharge of mirror neurons, rather than observations of the actions themselves. Umiltà et al. (2001) demonstrated that the majority of mirror neurons of rhesus monkeys respond during the observation of partially hidden actions, when full visual information about the action is not necessary to recognize the goal. The mirror neuron system also responds to the sound of a goal-related action, even when the monkey cannot see the action (Keysers et al., 2003; Kohler et al., 2002). These observations provide support for the interpretation that the mirror neuron system recognizes actions performed by other individuals and matches these actions on neurons that code the same action, providing the observer with the motoric perspective of the actor. It is through this interpretation that the mirror neuron system has garnered the attention of those interested in social learning.

A growing amount of information available from EEG, transcranial magnetic stimulation, functional magnetic resonance imaging (fMRI), and positron emission tomography (PET) studies indirectly supports the presence of a mirror neuron system in humans (reviewed in Rizzolatti \& Craighero, 2004). However, data suggest that there are some key differences between the mirror neuron systems of macaques and humans. For example, the mirror neuron system of humans, but not rhesus monkeys, responds to intransitive, meaningless movements. Perhaps this difference in sensitivity of the mirror neuron system sheds some light on the different imitative tendencies of humans and monkeys: Human children will "over imitate" (Horner \& Whiten, 2005), copying movements that are irrelevant to accomplishing the task. (For a more detailed review of the mirror neuron system, see Chapter 16.)

It is tempting to speculate that the mirror neuron system underlies social learning, given that the system allows for matching of the observation of motor actions with their execution. However, more data are needed on the involvement of motor neurons during the observation and acquisition of socially learned skills to understand whether mirror neurons are central to social learning processes. Furthermore, given that there are fundamental differences between macaques and humans in the properties of the mirror neuron system, data from additional species, ideally species that vary in their expression of social learning, will also be necessary to elucidate the role of the mirror neuron system in social learning.

\section{SPATIAL MEMORY}

Spatial memory can be very important to help animals navigate through their environments to find mates or food. Because closely related species differ in the degree to which they rely on spatial memory, the comparative approach has been extremely powerful for understanding the neural mechanisms that underlie these behavioral differences. Foraging and food-caching behavior vary between species in both corvids (crows, ravens, jays) as well as parids (chickadees, tits, titmice). Some species must store food each fall and remember the locations of storage sites in order to find food over the winter. The Clark's nutcracker from Arizona has been estimated to store up to 30,000 pine nuts each fall and appears to remember their locations even when the ground cover is transformed by snow (Balda \& Kamil, 1992). Because other species within the same family do not need to store food over the winter, some have predicted that the food-caching species will show greater 
spatial learning ability and greater spatial memory than closely related species that do not store food.

Several experimental studies support these predictions. Bednekoff, Balda, Kamil, and Hile (1997) showed that Clark's nutcracker and pinyon jays (Gymnorhinus cyanocephalus) had better memory for seed cache location up to 60 days than noncaching Mexican jays (Aphelecoma ultramarina) and western scrub jays (A. coerulescens), although all species showed good recall up to 250 days after learning. Bond, Kamil, and Balda (2007) found better serial reversal learning performance in highly social pinyon jays compared with Clark's nutcracker and Western scrub jays. Western scrub jays, in contrast, are able to learn to avoid caches where stored food has spoiled with passage of time, suggesting that scrub jays have a form of declarative memory that involves not only space but also time (Clayton, Yu, \& Dickinson, 2001). Therefore, each species of corvid has particular abilities that serve functions appropriate for that species.

In rodents, Barkley and Jacobs (2007) found that Merriam's kangaroo rat (Dipodomys merriami), which hoards food, was more accurate in remembering locations for food than the nonhoarding Great Basin kangaroo rat $(D$. microps). Monogamous versus polygynous species differ in spatial memory requirements because males of monogamous species have relatively small territories and home ranges relative to those of males from polygynous species that must travel over a wider range to locate multiple females. Gaulin and Fitzgerald (1989) hypothesized that polygynous male meadow voles (Microtus pennsylvanicus) would learn spatial mazes more rapidly than females of the same species, whereas there would be no sex differences between males and females of monogamous pine and prairie voles (M. pinetorium and $M$. ochrogaster). Using a series of Hebb-Williams spatial mazes, Gaulin and Fitzgerald found a sex difference in polygynous voles with males learning faster, but, as predicted, there was no sex difference in maze acquisition in monogamous voles.

\section{Brain Mechanisms and Spatial Memory}

The hippocampus is known as a primary region involved in both spatial memory and in transforming short-term to longterm memories. Several studies have shown differences in hippocampal volume, or the structure of neurons within the hippocampus, as a function of ecological differences. Birds from 3 seed-caching families had greater hippocampal volume relative to both body weight and brain volume than birds from 10 families that do not cache seeds (see Figure 3.4; Sherry, Jacobs, \& Gaulin, 1992). Hampton and Shettleworth (1996) found large hippocampal volume and better spatial nonmatching-to-sample performance in food-storing black-capped chickadees (Poecile atricapillus) compared with nonfood-storing dark-eyed juncos

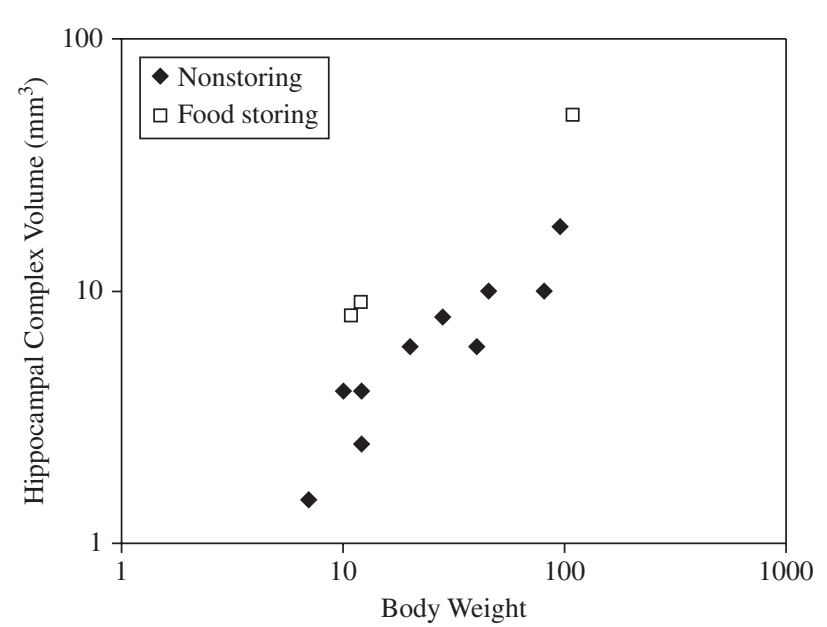

Figure 3.4 Hippocampus volume plotted against mean body size for 13 families of birds.

Open symbols indicate families with some species that store food. Both axes are plotted logarithmically. (Adapted from Sherry, Jacobs and Gaulin, 1992)

(Junco heyemalis). Within these species, there is also variation in caching behavior, spatial memory, and hippocampal volume. Pravosudov and Clayton (2002) compared chickadees from Alaska (where food resources are scarce) with those from Colorado and found that Alaskan birds cached more food, recovered food more efficiently, were more accurate on spatial (but not on nonspatial) learning tasks and had greater hippocampal volume with more neurons. Migratory subspecies of juncos (which presumably have greater need for spatial memory) performed better than nonmigrating juncos in a spatial memory task and had more densely packed neurons in the hippocampus.

Polygynous male meadow voles, which must travel over a greater distance to find multiple females than monogamous males or females of either type, also had larger hippocampal volume than females and than either sex of monogamous pine voles (see Figure 3.5; Jacobs, Gaulin, Sherry, \& Hoffman, 1990). As noted previously, polygamous males also were faster to solve multiple spatial maze problems than were polygamous females, whereas monogamous males and females were equal in solving spatial mazes (Gaulin \& Fitzgerald, 1989).

However, increased hippocampal volume is not universally found in species that do more seed caching. Pravosudov and de Kort (2006) found that noncaching Western scrub jays had similar hippocampal volumes to food-caching European jackdaws (Corvus monedula), and Brodin (2005) found that willow tits (Parus montanus) from Europe had twice the hippocampal volume of blackcapped chickadees but did not differ in food hoarding behavior. We cautioned earlier about accepting size alone as a measure of complexity. Precise measures of neuronal 

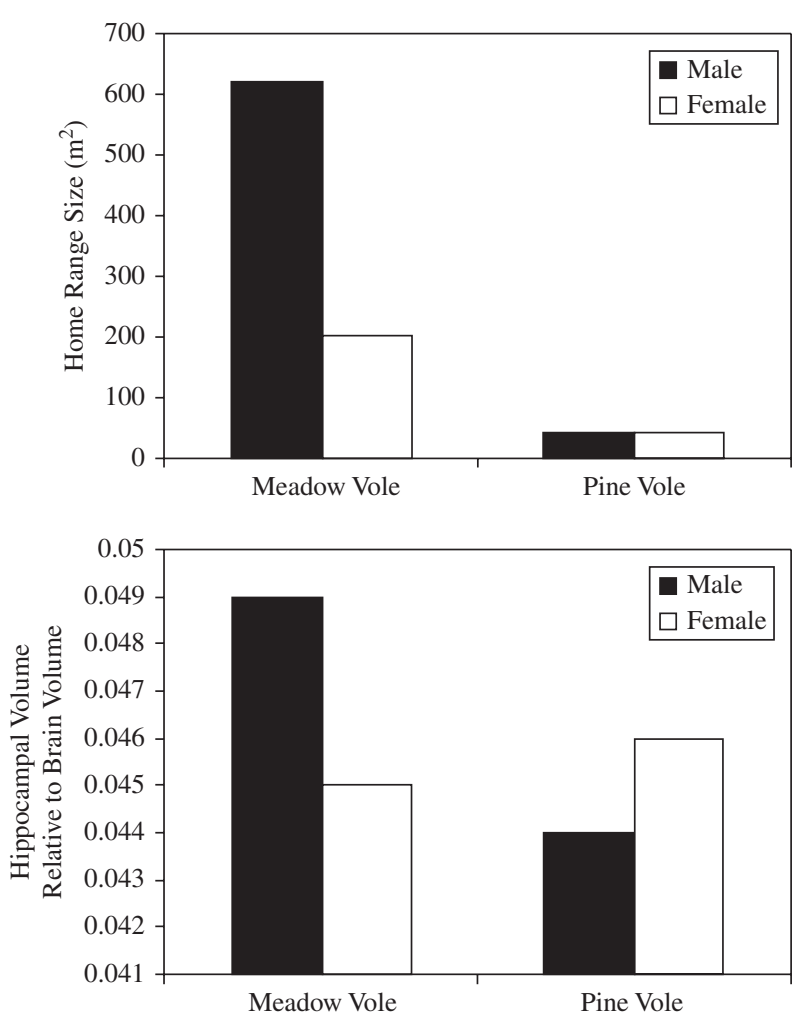

Figure 3.5 Home range size and relative volume of hippocampus in polygamous meadow voles and monogamous pine voles. Male meadow voles have significantly greater home range sizes and hippocampus volume than female meadow voles and monogamous voles of either sex. (Adapted from Jacobs, Gaulin, Sherry \& Hoffman 1990)

number, density, and dendritic fields may be more accurate measures of brain differences across species. Much more than spatial memory may be involved in food caching, such as remembering about food quality and time of storage (Clayton, 1998). This suggests that not only the hippocampus but many other brain areas may be involved in cognitive processes relating to foraging and food caching.

\section{COOPERATION, RECIPROCITY, AND DONATION}

Cooperative behavior emerges numerous times throughout the animal kingdom and, as is the case for social learning, its presence does not fit with a simple phylogenetic or brain size explanation. Cooperative interactions between conspecifics can be divided into two categories based on the distribution of costs and benefits to the actors. In one form of cooperation, cooperation for mutual benefit, the act is beneficial to all individuals involved (West, Griffin, \& Gardner, 2007). The second form of cooperation occurs when one individual incurs a cost, albeit potentially temporary, while providing a benefit to a second individual. From an evolutionary perspective, this costly form of cooperation is most often accounted for by kin selection (W. D. Hamilton, 1964) or reciprocal altruism (reciprocity; Trivers, 1971).

The most commonly observed form of mutually beneficial cooperation is cooperative hunting (Packer \& Ruttan, 1988). Data from African wild dogs (Lycaon pictus) and spotted hyenas (Crocuta crocuta) demonstrate that hunting success, prey mass, and the probability of multiple kills increased with the number of adults taking part in the hunt (Creel \& Creel, 1995; Drea \& Frank, 2003). Mutually beneficial cooperative hunting also occurs among African lions (Panthera leo; Schaller, 1972; Scheel \& Packer, 1991). In the open plains of Etosha National Park in Namibia, lionesses have acquired preferential hunting roles within their pride, and hunts were more likely to be successful when the group size was large and huntresses occupied their preferred roles (Stander, 1992). Elaborate displays of cooperative hunting have also been observed in some wild populations of chimpanzees (Pan troglodytes; Boesch \& Boesch, 1989; Gilby, Eberly, \& Wrangham, 2008). Cooperative hunting is not limited to megavertebrates, however. A South American spider (Anelosimus eximius) weighing approximately $1 \mathrm{mg}$ works in groups of a few to several thousand individuals to construct large basket-shaped webs that cover several cubic meters, allowing the spiders to cooperatively capture and subdue prey up to 30 times their own body size (Rypstra \& Tirey, 1991).

Mutually beneficial cooperation occurs outside of the hunting context as well. For example, many species exhibit mobbing, which is an antipredator behavior characterized by multiple individuals simultaneously attacking or harassing a predator. This behavior has been observed in mammals, fish, birds, and insects (Bartecki \& Heymann, 1987; Curio, 1978; Dominey, 1983; Hennessy \& Owings, 1978; Hoogland \& Sherman, 1976; Shields, 1984). Other examples of mutually beneficial cooperative behavior include alliance formation, in which two or more individuals combine efforts against a third (reviewed in Dugatkin, 2002); mutual grooming (Dugatkin, 1997); and even cooperative mate acquisition (DuVal, 2007).

Cooperative interactions that are not mutually beneficial are more difficult to explain within evolutionary theory. If one actor incurs a cost and a second actor acquires a benefit, the question arises as to why the first actor takes part in the costly act. If the individuals are related, then kin selection is the mechanism most commonly referenced to account for this behavior. It is assumed that costs incurred by the actor are offset by the indirect fitness benefits obtained through increasing the survival of relatives with shared genes (W. D. Hamilton, 1963). Well-documented examples of kin selection include cooperative breeding or helping at the nest, whereby reproductively mature individuals remain in 
their natal group to assist in the rearing of younger siblings (behavior in birds reviewed in Brown, 1987; behavior in mammals reviewed in Solomon \& French, 1997).

If the individuals are unrelated, then reciprocal altruism (Trivers, 1971) is often credited as the mechanism for maintaining the apparently costly behavior. Under reciprocal altruism, one individual incurs a cost and provides a benefit to a second individual at present, and at a later time the benefit is repaid by the second individual. In his seminal paper, Trivers listed the following factors that should increase the likelihood of reciprocal altruism occurring in a species: (a) long life span, (b) low dispersal rate, (c) high degree of mutual dependence, (d) extensive parental care, (e) lack of strong dominance hierarchies, and (f) tendency to aid in combat. Examples of reciprocal altruism in the wild include reciprocal sharing of blood meals by vampire bats (Desmodus rotundus; Wilkinson, 1984), predator inspection by sticklebacks (Gasterosteus aculeatus; Milinski, 1987), and reciprocal grooming in impalas (Aepyceros melampus; Hart \& Hart, 1992). However, many have argued that empirical evidence for reciprocity is lacking and that, although the idea of reciprocity is theoretically appealing, its occurrence is extremely rare outside of humans (Hammerstein, 2003; Stevens \& Hauser, 2004).

Schuster and colleagues (Schuster, 2002; Schuster \& Perelberg, 2004) have argued that coordinating behavior with a conspecific, often one involved in cooperative behavior, may be intrinsically rewarding. They posited from experiments on rats that economic analyses of the costs and benefits of cooperative interactions would not provide enough information to an outside observer to determine whether the cooperative interaction was beneficial to an actor because intrinsic rewards also play a role, as they do in other social interactions. This hypothesis remains to be tested on additional species and in varying contexts, but it provides a novel way of thinking about when cooperative behavior may emerge across taxa when economic reasoning falls short of explaining observed cooperative behavior.

Investigations of cooperation historically focused on the selective pressures that could lead to its emergence (Alexander, 1974; Axelrod \& Hamilton, 1981; Brown, 1983; I. M. Hamilton, 1963; W. D. Hamilton, 1964; Mayr, 1961; Trivers, 1971). However, interest in the proximate mechanisms of cooperation has grown (Brosnan \& de Waal, 2002), and this may explain why cooperative behavior emerges in some taxa but not others. Recent studies have included investigations into the actors' understanding of the partner's role in the cooperative act, the effects of various spatial and temporal reward distributions on cooperative performance, the impact of the relationship between actors on their ability to cooperate, the social system of the species presented with an opportunity to cooperate, and the cognitive skills required to cooperate.

Understanding of the partner's role in a cooperative act varies across species. Boesch and Boesch (1989) were the first to call attention to and distinguish between cooperation in which the actors take into account their partner's behavior and cooperation in which individuals are mutually attracted to the same resource and act independently of one another. The authors conceptually organized the hunting behavior of wild chimpanzees into four categories of increasing complexity based on the degree to which actors integrated their own behavior with that of their partner. This categorization scheme has been subsequently used to understand partner interactions in many cooperative contexts (Chalmeau, Lardeux, Brandibas, \& Gallo, 1997; Chalmeau, Visalberghi, \& Gallo, 1997; Cronin et al., 2005; Mendres \& de Waal, 2000).

Great apes (including humans) appear to understand the role their partner plays in a cooperative act and adjust their behaviors accordingly (Brownell, Ramani, \& Zerwas, 2006; Chalmeau \& Gallo, 1996a, 1996b; Chalmeau,Lardeux, et al., 1997). Variables used to evaluate understanding of the partner typically include measures of attempts to solve the apparatus in the absence of the partner and glances exchanged between actors. Investigations of whether monkeys understand the role of their partner have produced mixed results both within and across species. Some studies with tufted capuchin monkeys demonstrated that capuchins did not take into account the role of their partner when confronted with a cooperative task. The subjects solved the task but did so by chance alone, as determined by the high number of uncoordinated attempts by each actor (Chalmeau, Visalberghi et al., 1997; Visalberghi, 1997; Visalberghi, Pellegrini Quarantotti, \& Tranchida, 2000). Others have argued that capuchin monkeys can solve a cooperative task and take into account their partner's role when the task design is intuitive, that is, when the subjects are able to see how the apparatus works and presumably understand the effects their actions have on the apparatus (Mendres \& de Waal, 2000). We investigated the extent to which pair-bonded cotton-top tamarins understood the role of their partner in a cooperative problem-solving task and found that tamarins adjusted their behavior based on the presence or absence of their partner (Cronin et al., 2005), providing evidence that cotton-top tamarins are capable of understanding their partner's role in a cooperative task. Whether an individual will attend to a partner's behavior will likely vary with the amount of behavioral coordination and attentiveness to social cues typically expressed by that species.

Intra- and interspecific variation in cooperation may be affected by the relationship between actors, as is the case 
for social learning. As argued by van Schaik and Kappeler (2006), individuals bonded over an extended length of time likely do not evaluate the immediate costs and benefits of their behavior but rather evaluate the long-term benefits and costs exchanged throughout the relationship. Dominance asymmetries may also affect cooperative success, either in the form of coercion by dominants to solve the task or avoidance of the task by subordinates (Chalmeau, 1994; Chalmeau \& Gallo, 1996b; Chalmeau, Lardeux, et al., 1997; Tebbich, Taborsky, \& Winkler, 1996). Melis, Hare, and Tomasello (2006) have found that tolerance of cofeeding in chimpanzee dyads is predictive of their success on a cooperative task.

In addition, the social characteristics of a species (e.g., their characteristic degree of tolerance for nearby conspecifics, behavioral coordination, and mutual dependence) may influence the likelihood of successful cooperation (Snowdon \& Cronin, 2007). Trivers (1971) noted that in species with strong dominance hierarchies, the likelihood of reciprocal altruism is reduced. Because of high levels of intragroup competition in Guinea baboons (Papio papio), Japanese macaques (Macaca fuscata), and rhesus macaques ( $M$. mulatta), these species did not coordinate efforts to move heavy food-baited stones (Burton, 1977; Fady, 1972; Petit, Desportes, \& Thierry, 1992), whereas Tonkean macaques (M. tonkeana), which are characterized by less strict dominance hierarchies and greater social tolerance, were more often successful at coordinating their actions to displace the baited stone (Petit et al., 1992). Consistent with the idea that social context can predict performance on cooperative tasks are the observations that chimpanzees, characterized by a strict dominance hierarchy and low social tolerance, performed better on competitive tasks than cooperative tasks (Hare \& Tomasello, 2004) and that the socially tolerant bonobos outperformed chimpanzees on cooperative tasks (Hare, Melis, Woods, Hastings, \& Wrangham, 2007).

Attempts to investigate the evolutionary origins of the human tendency to act in the best interest of others (i.e., to act prosocially) have led to interesting results. Initial investigations into the evolutionary origins of prosociality indicated that humans' closest living relatives, chimpanzees, overwhelmingly refused to donate food to a social partner, even when the potential donor could do so with very little effort and could not obtain the food for itself (Jensen et al., 2006; Silk et al., 2005; Vonk et al., 2008). One interpretation that followed from these findings was that the human tendency to act prosocially must have emerged recently in our evolutionary history because the trait was not present in the common ancestor of chimpanzees and humans. However, as we cautioned earlier in this chapter, convergent as well as divergent evolution should be considered. Some evidence has emerged to indicate that prosocial tendencies may be evident elsewhere in the primate order, more specifically in a species that exhibits a social system similar to that of humans: the cooperatively breeding common marmoset. Burkart and colleagues (2007) have shown that common marmosets donated food to conspecifics in a task nearly identical to that used with chimpanzees. The authors interpreted their findings as evidence that a cooperatively breeding social system, one shared by humans and cooperatively breeding marmosets and tamarins, is key to the emergence of prosocial tendencies. Additional research is needed to determine whether the social systems of the species are the most important factor in these findings, as marmosets and chimpanzees differ in many other ways as well. However, these initial results highlight the importance of considering social factors in addition to phylogeny.

Discussions of cognitive requirements for cooperation are most often made in relation to the ability to understand the role of the partner, as discussed previously, or the ability to engage in reciprocal altruism. Some have argued that the paucity of empirical evidence for reciprocal altruism is due to its steep cognitive demands (Hammerstein, 2003; Stevens $\&$ Hauser, 2004). Cognitive skills hypothesized to be necessary for reciprocal altruism include numerical quantification, time estimation, delay of gratification, detection and punishment of cheaters, analysis and recall of reputation, and inhibitory control (Stevens \& Hauser, 2004). To date, these cognitive requirements have been discussed only on theoretical grounds and have not been examined empirically.

Others assert that reciprocal altruism does not require complex cognition. Two forms of reciprocal altruism that do not require advanced cognition have been put forth. The first is generalized reciprocity, in which individuals decide whether to cooperate based on prior experiences, irrespective of the identity of the current partner (Pfeiffer, Rutte, Killingback, Taborsky, \& Bonhoeffer, 2005). Generalized reciprocity does not require analysis and recall of individual reputations. This concept has been well exemplified in recent studies with Norway rats (Rattus norvegicus; Rutte \& Taborsky, 2007, 2008). The second form of reciprocal altruism is symmetry-based or attitudinal reciprocity. Symmetry-based reciprocity occurs when closely bonded individuals help one another without stipulating returns. Because of the symmetrical and long-lasting characteristics of the relationship, the benefits generally balance out over a lifetime without the need for any purposeful "scorekeeping" (de Waal \& Luttrell, 1988).

We have found that unrelated, pair-bonded cottontop tamarins not only cooperate for mutual rewards but also cooperate when rewards are reciprocally distributed between actors and when rewards are repeatedly received by a single individual in the dyad. The tamarins were sensitive to the reward scenarios, cooperating most consistently 
for mutual rewards and least consistently when the rewards repeatedly went to the same individual, but cooperation persisted nonetheless (Cronin et al., 2005; Cronin \& Snowdon, 2008). The tamarins' cooperative performance in this study may have been due to attitudinal reciprocity as described by de Waal and Luttrell (1988); that is, the tamarins were cooperative with their long-term mates without keeping track of the exact costs and benefits incurred. Further studies of cooperation in tamarin dyads that differ in their social relationships are needed to further test this interpretation.

As with the other phenomena discussed here, cooperative behavior emerges throughout the animal kingdom with little regard for phylogeny. Investigations into the social organizations of species and the social relationships within species have proved the most fruitful for explaining and predicting species and individual differences. Unfortunately, little is known about the neural processes that underlie cooperative interactions in nonhuman animals. However, scientists can gain some insight and begin to make predictions about neural involvement from recent studies performed on the most cooperative species: humans.

\section{Cooperation and the Brain}

Studies emerging from the nascent field of neuroeconomics have begun to elucidate some of the regions of the brain involved in human cooperative behavior (see also McCabe, this volume). These studies have primarily used fMRI data collected while humans engage in cooperative games. However, a single cooperative interaction necessarily includes multiple sequential stages, including the stage in which an individual decides whether to cooperate and the stage in which he or she experiences the outcome of the cooperative interaction. Each stage is likely to recruit different brain regions, and fMRI investigations have aimed to isolate different stages of cooperative interactions.

A recent fMRI study utilized the prisoner's dilemma to evaluate neural activation during the initial stage of cooperation, when participants decided whether to cooperate with a confederate. The prisoner's dilemma is a widely used game in which two individuals are given the simultaneous choice either to cooperate with the other individual or to defect. The payoff to the individual depends on his or her own choice and the choice of the partner, which is revealed once both individuals have made their choices. Regardless of the other player's choice, the choice to defect yields a higher payoff than the choice to cooperate. But if both players defect, both do worse than if both had cooperated (see Figure 3.6A). Rilling et al. (2007) contrasted activations when the participant decided to cooperate with those when the participant decided to defect. Results indicated that the choice to defect was associated with stronger activation in the rostral anterior cingulate cortex (rACC) and the dorsolateral prefrontal cortex (DLPFC). The activation of the rACC and the DLPFC is interesting because the DLPFC is often associated with executive control and goal maintenance and the $\mathrm{rACC}$ with the processing of aversive experiences and the detection of cognitive conflict. This pattern of activation seems to indicate that defection is not a simple, favorable choice by participants. The choice to cooperate was correlated with activation in the orbitofrontal cortex (OFC; see Figure 8.12 in Chapter 8). The OFC has been implicated in the processing of rewarding and punishing factors and in emotional decision making (Bechara, Damasio, \& Damasio, 2000; Ichihara-Takeda \& Funahashi, 2006). Furthermore, Rilling et al. (2007) found

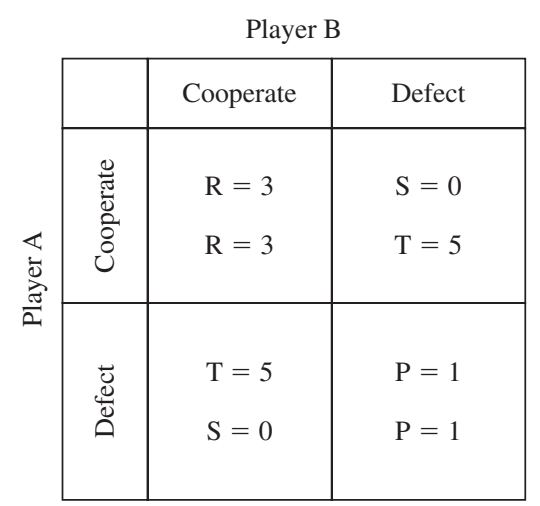

(A)

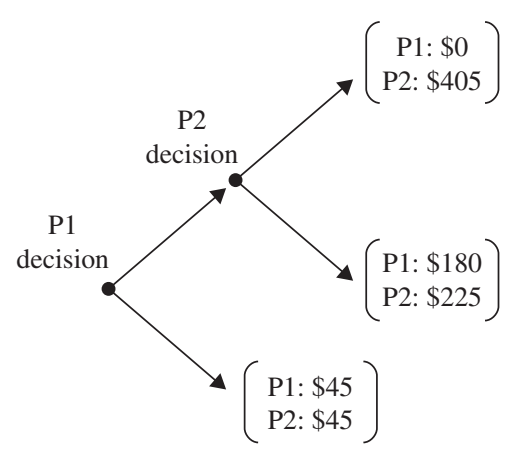

(B)

Figure 3.6 A. Prisoner's dilemma matrix. Payoff awarded to Player A is the top value within each cell; payoff awarded to Player B is the bottom value within each cell. Different payoff values can be used, however this rule must be followed: T $>$ R $>$ P $>$ S.

B. Trust game diagram. Each node represents a point at which a player must make a decision. At the first node, Player 1 either decides to split the benefits equally, or to allow Player 2 a move. If Player 1 decides to allow Player 2 a decision, the pot increases and both the potential gain and loss increase for Player 1. Player 2 then decides between an option that allows both players rewards but provides him/ herself with a greater reward, or an option that provides him/herself with all the rewards. Different payoff values can be used. (Diagram modified from McCabe et al., 2001). 
a negative correlation between OFC and DLPFC activation that they interpreted as interplay between emotional and cognitive control leading up to the execution of cooperation or defection.

Additional insight into the brain regions recruited during the decision to cooperate with another individual comes from fMRI investigations of humans engaged in a trust game that required individuals to decide whether to invest money in a second individual who could increase or decrease the payoff to the first individual (see Figure 3.6B). The investigation revealed that those participants who consistently attempted cooperation exhibited more specific prefrontal cortex (PFC) activation when playing the game with a human as compared to a computer employing a fixed, known probabilistic strategy (McCabe, Houser, Ryan, Smith, \& Trouard, 2001). However, differential PFC activation between social and nonsocial versions of the game was not found for individuals who rarely cooperated. Using another version of the trust game, King-Casas et al. (2005) reported that the magnitude of neuronal activity in the dorsal striatum correlated with the intention to trust the other player, and the peak of the response shifted earlier in the decision process as player reputations developed in this reciprocal game. Rilling et al. (2002) found that different patterns of neural activation determined by whether the playing partner was identified as a computer or a human. Greater activation was observed in the anteroventral striatum, the rACC, and the OFC during social cooperation than during cooperation with a computer. The OFC and ventral striatum are recruited while one is anticipating an economic reward (e.g., Padoa-Schioppa \& Assad, 2006; Roesch \& Olson, 2004; Schultz, Dayan, \& Montague, 1997), however Rilling et al. (2002) controlled for monetary gain in the social versus nonsocial contrast.

Some investigations have specifically examined the differences in neural activation following a potentially cooperative interaction. Using the prisoner's dilemma and fMRI, Rilling, Sanfey, Aronson, Nystrom, and Cohen (2004) found that participants displayed increased neural activity in the ventral striatum in response to reciprocated interactions and decreased neural activity in the ventromedial PFC in response to unreciprocated interactions. The authors interpreted these results to indicate that the mesolimbic dopamine system processes errors in predictions about whether a social partner will act reciprocally.

In fact, many of the regions recruited during cooperative interactions are the same regions classically involved in processing reward. The neural circuitry often involved in reward includes the caudate and particularly the ventral striatum, amygdala, and the medial and orbital PFCs (reviewed in Cardinal, Parkinson, Hall, \& Everitt, 2002; see also Volume 2, Chapter 40). It is interesting that even when the effects of tangible rewards are controlled, social cooperative interactions continue to engage some of the reward circuitry, suggesting that cooperating with another individual may be intrinsically rewarding. Similarly, Harbaugh, Mayr, and Burghart (2007) found that voluntary monetary donations also increase the neural activity of reward regions. It seems that data obtained from neuroscientific investigations as well as behavioral observations (i.e., Schuster, 2002; see above) converge to support the hypothesis that acting cooperatively with conspecifics is rewarding, and because these regions are rich in dopamine, it is likely that dopamine is involved in these cooperative interactions.

The neuropeptide oxytocin may also be involved in cooperative social interactions. Oxytocin is a nonapeptide produced in the supraoptic and paraventricular nuclei of the hypothalamus. Oxytocin is released into the periphery from magnocellular neurons of the supraoptic nuclei, which project to the posterior pituitary. In addition, oxytocin is released centrally from parvocellular neurons of the paraventricular nuclei (Uvnas-Moberg, 1998). Oxytocin has been identified repeatedly in the coordination of positive social interactions in a wide range of species (reviewed in Uvnas-Moberg, 1998). In addition to having a well-known role in the onset of uterine contractions, milk letdown, and mother-infant bond formation (Gimpl \& Fahrenholz, 2001; Levy, Kendrick, Goode, Guevara-Guzman, \& Keverne, 1995; Nelson \& Panksepp, 1998), oxytocin facilitates the formation and maintenance of important relationships outside the mother-infant context. Oxytocin is integral to the formation of pair bonds in monogamous voles (Carter, 1998; Carter, DeVries, \& Getz, 1995; Young, 1999; see Box 3.1 and below).

Oxytocin correlates with the expression of trust in humans (Zak, Kurzban, \& Matzner, 2005) and increases the amount of generosity (donation) in humans (Zak, Stanton, \& Ahmadi, 2007). Furthermore, treatment with oxytocin increases one's willingness to accept risk in interpersonal interactions (Kosfeld, Heinrichs, Zak, Fischbacher, \& Fehr, 2005). Because of the involvement of oxytocin in positive social interactions, some have begun to speculate that oxytocin may play a role in prosocial behaviors such as cooperation, reciprocity, and donation (i.e., Rutte \& Taborsky, 2007).

The term cooperation is used in different ways by economists, psychologists, and ethologists, and, as we have shown, investigations of cooperative behavior have spanned studies of individuals acting altruistically, engaging in reciprocity, taking risks for kin, providing benefits to mates, and engaging in economic games. The common link in all of these forms of cooperation is that they provide a benefit of some sort for another individual, and the most information known so far about the brain has come from humans engaged in neuroeconomic games. However, these patterns of neuronal activation provide just a starting point for investigations of other forms of cooperative 


\section{BOX 3.1 OXYTOCIN AND VASOPRESSIN}

Oxytocin (OT) and arginine vasopressin (AVP, also known as antidiuretic hormone) are closely related in structure but have different physiological roles. Both are made of nine amino acids (peptides) folded into a ring, and the two hormones differ in only two amino acids. These hormones are released into the blood from the posterior pituitary gland at the base of the brain, but they are also released from neural tissue in the hypothalamus and are active in several areas of the brain.

Until 20 years ago, the best known role for these hormones was in the regulation of peripheral physiological processes. OT is involved in uterine contractions at birth (and indeed a synthetic version of OT is frequently used to induce labor) and in the milk letdown reflex in nursing. AVP is involved in the contraction and relaxation of smooth muscle (e.g., blood vessels) and regulates transport of water and sodium across cell walls, especially in the kidney.

In recent years, other behavioral functions of these hormones have become widely known. OT is involved in the formation of pair bonds in monogamous female rodents (Carter, 1998), and AVP is involved in pair bond formation in monogamous male rodents. AVP is also involved in the aggressive behavior shown by territorial monogamous male rodents (Marler et al., 2003). AVP also plays a role in paternal behavior in monogamous rodents (Marler et al., 2003), and OT plays an important role in regulating female sexual behavior and maternal behavior.

Both hormones are anxiolytic (i.e., they reduce anxiety), and release of OT during deep massage, stroking, and sexual intercourse has been hypothesized to play an important role in social bonding in humans. Indeed Gonzaga, Turner, Keltner, Campos, and Altemus (2006) found that OT levels increased during displays of romantic love, but not sexual arousal, in college women, suggesting a role of OT in human pair bonding and social reinforcement.

behavior. Much more information is needed to determine whether species that typically cooperate with one another, such as cooperatively hunting hyenas, have regional specializations or patterns of neuronal activation that differ from those of species that do not typically cooperate with one another. If a comparative neuroscience approach were to be applied to cooperative behavior, one might speculate that in species in which it is beneficial to act cooperatively with conspecifics, cooperative behavior will have become associated with the brain's reward system throughout the evolutionary history. But hypotheses of this sort remain to be tested.

\section{PAIR BONDS}

In many mammalian species, close affiliative relationships between males and females outside of mating are rare. The closest relationships are found in species with biparental or cooperative care such as prairie voles, titi monkeys, tamarins, and marmosets. In mammals, females incur the costs of gestation and lactation, and males can never be certain of paternity of infants. Under such conditions, it has been assumed that males will be more successful attempting to fertilize as many females as possible rather than investing in parental care. However, in species with biparental or cooperative care, fathers often play a critical role in infant survival, and thus the reproductive success of both parents depends on joint infant care. Biparental, socially monogamous species are expected to have closer, more affiliative social relationships than polygamous species, and it is, in fact, under these conditions that close relationships between mates are found.

The formation of the relationship has been well studied. Williams, Catania, and Carter (1992) found that prairie vole females cohabiting with a male for 24 hours with or without mating developed a strong bond. Cohabitation with mating for less than 24 hours, but not cohabitation alone, also led to pair formation. Savage, Ziegler, and Snowdon (1988) found that newly paired cotton-top tamarins spent more time in contact, in grooming, and engaged in sexual activity than did established pairs, with males initiating affiliation more often than females. Widowski, Porter, Ziegler, and Snowdon (1992) found that exposure to a novel cottontop tamarin male with no direct physical contact led to ovulation in reproductively suppressed female cotton-top tamarins. Schaffner, Shepherd, Santos, and French (1995) also found that male black tufted-ear marmosets (Callithrix kuhli) initiated more proximity behavior in the first 40 days after pairing and that sexual behavior decreased over time. Silva and Sousa (1997) studied variation in pair formation in sexually naive common marmosets and found that those that became pregnant within the first 10 weeks had more affiliative behavior, especially grooming, and greater coordination of behavior than those pairs that did not conceive immediately. This is the only study on the reproductive consequences of within-species variation in pair formation.

Determination that a pair bond exists requires some experimental documentation of attachment: that an animal is distressed upon separation from its mate and displays 
greater affiliation than baseline upon reunion, that an individual will behave aggressively toward intruders, or that an individual will preferentially seek contact with its mate when given a choice between conspecifics. Mendoza and Mason (1986b) found greater disturbance, more aggression to intruders, and higher cortisol levels in the monogamous titi monkey (Callicebus moloch) compared to the polygynous squirrel monkey (Saimiri sciureus). When separated and offered a choice between mate and infant, titi monkeys chose their mates preferentially. Infants that were separated from both parents chose fathers over mothers (Mendoza \& Mason, 1986a). Subsequently, when paired adult titi monkeys were separated for 30 min or 5 days and tested with either their mate or an opposite-sex stranger, male and female titi monkeys showed equal affiliation upon reunion with the mate. In contrast, they showed high levels of arousal when placed with an opposite-sex stranger. These results suggest strong and lasting relationships (FernandezDuque, Mason, \& Mendoza, 1997).

Cotton-top tamarins also exhibit distress when separated from mates for short time periods, with increased rates of long calling (which is used for within-group cohesion and by lost animals) during the period of separation and increased affiliative and sexual behavior when reunited after separation (Snowdon \& Ziegler, 2007). Males are more vocal and appear more disturbed by separation than females. They also display levels of aggression toward intruders of both sexes, with males displaying equal amounts whether the mate is present or absent and females displaying higher levels only in the presence of the mate. Males also groom females significantly more often than females groom males (Snowdon \& Ziegler, 2007). All of these results suggest that males are more responsible for maintaining relationships than females.

Partners in pair-bonded species can also buffer against the effects of stress. T. E. Smith and French (1997) tested male and female tufted-ear marmosets in novel environments and found that levels of cortisol were lower when pairs were together in a novel environment than when they were alone. Rukstalis and French (2005) played back calls of the mate to isolated marmosets and found that the calls alone reduced cortisol levels as well as stress-related behavior.

In summary, lasting adult heterosexual affiliative relationships are found in a few species that are socially monogamous or cooperatively breed. Several studies have looked at behavioral changes during pair formation and have evaluated attachment through studies involving challenges by unfamiliar animals of same and opposite sex and studies involving separation and reunion. The individual recognition of a specific individual as a mate and the differential response to the mate than to other potential mates are also key components of a pair bond. What are the neural and hormonal mechanisms that maintain these relationships?

\section{Role of Oxytocin and Vasopressin}

Oxytocin is a neuropeptide that has been implicated in affiliative relationships. In the past 15 years, extensive research, primarily on monogamous voles, has indicated the importance of oxytocin in formation of affiliative relationships, especially in females (for reviews, see the following: mother-infant relationships, Nelson \& Panksepp, 1998; and heterosexual adult relationships, Carter, 1998; Carter et al., 1995; Insel, 2003). Oxytocin, but not the closely related nonapeptide vasopressin, appears critical for female prairie voles in relationship formation (Insel \& Hulihan, 1995). However, vasopressin levels increase in male prairie voles after pair formation, suggesting a sex difference in which hormones are involved in a pair bond for these rodents (Winslow, Hastings, Carter, Harbaugh, \& Insel, 1993). In non-pair-bonding species of voles, oxytocin is not effective for inducing a pair bond and has a different distribution of receptors in the brain (reviewed by Young, 1999). Nonetheless, oxytocin infused chronically into male rats (a polygamous species) led to increased social interactions (Witt, Winslow, \& Insel, 1992). Pedersen and Boccia (2002) found that oxytocin was critical for initiation and maintenance of sexual behavior in female rats. Oxytocin injected into the medial preoptic area of male rats also facilitated social recognition, whereas vasopressin did not (Popik \& van Ree, 1991). However, Dantzer, Koob, Bluthé, and Le Moal (1988) reported that vasopressin in the septal region facilitated social memory in rats. Oxytocin knockout mice fail to recognize familiar conspecifics, and oxytocin administered to the medial amygdala prior to initial exposure facilitated social recognition (Bielsky \& Young, 2004; Ferguson, Aldag, Insel, \& Young, 2001).

Rosenblum et al. (2002) compared highly affiliative bonnet macaques (Macaca radiata) with socially distant pigtail macaques ( $M$. nemestrina) and found that the more affiliative bonnet macaques had higher cerebrospinal fluid oxytocin levels and lower corticotrophin-releasing hormone levels than the pigtail macaques. Winslow, Noble, Lyons, Sterk, and Insel (2003) reported that mother-reared male rhesus macaques had elevated cerebrospinal fluid oxytocin levels compared with nursery-reared macaques, and there was a significant correlation between oxytocin levels and affiliative behavior. In contrast, vasopressin levels did not differ with rearing condition but correlated positively with fearful behavior in rhesus macaques.

Interest in oxytocin in humans has increased recently because of the role of oxytocin in both mother-infant 
attachment and adult affiliative behavior. Wismer Fries, Ziegler, Kurian, Jacoris, and Pollak (2005) found that children had elevated oxytocin levels when performing a task that included contact by the mother but not contact by an unfamiliar female. In contrast, children adopted from Eastern European orphanages several years previously showed low oxytocin responses to both adopted mothers and an unfamiliar female, indicating that early experience affects the oxytocin system. Oxytocin administered intranasally increases trust among humans (Kosfeld et al., 2005; Zak et al., 2005). Infusions of oxytocin into people with autism and with Asperger syndrome reduced repetitive behavior (Hollander et al., 2003) and increased retention of social cognition (Hollander et al., 2006). These studies support the role of oxytocin in producing calm behavior and facilitating social memories in humans. Turner, Altemus, Enos, Cooper, and McGuinness (1999) found that women asked to recount a negative experience of loss or abandonment showed decreased levels of serum oxytocin correlated with the degree of negative emotion expressed. Using data from Turner et al. (1999), Gonzaga et al. (2006) reported that women engaging in affiliation signals with a romantic partner had a significant positive correlation between the amount of positive signaling and serum oxytocin. Grewen, Girdler, Amico, and Light (2005) reported higher plasma oxytocin in both men and women in relationships with strong partner support. Thus, changes in oxytocin appear to track affiliative and positive emotional states in both sexes and across many species. In humans, peripheral measures of oxytocin levels appear to correlate with differences in affiliation, and peripheral infusions of oxytocin can increase affiliative behavior and social memory.

Most comparative research on pair bonds has involved evaluating species differences; however, within-species individual differences in relationship quality and hormonal correlates are found in nonhuman primates as well. We have observed a fivefold variation in the amount of affiliative behavior between pairs of cotton-top tamarins and have also observed a fivefold variation in urinary oxytocin levels in both sexes that correlates with the amount of affiliative behavior expressed. Variation in sexual behavior explains most of the variance in male oxytocin levels, whereas variation in contact and grooming explains most of the variance in female oxytocin levels (Snowdon et al., in preparation).

In summary, there is clear evidence for the importance of oxytocin for pair bonding in females of monogamous vole species and for the importance of vasopressin in male voles. Oxytocin can supersede the effects of mating in pair bond formation. Oxytocin affects sexual behavior in female rodents and macaques and also appears to be important for social recognition in male rodents. In rodents, tamarins, and human primates, peripheral measures of oxytocin appear to be correlated with affiliation, attachment, trust, and positive emotions, and peripheral administration of oxytocin can alter affiliative behavior.

\section{Brain Mechanisms}

Comparative work between monogamous and polygynous voles has shown that monogamous female voles but not polygamous voles have increased oxytocin receptor density in the nucleus accumbens and caudate putamen and greater vasopressin receptor density in the ventral pallidum (Table 3.2; Young \& Wang, 2004). Little is known about oxytocin distribution in monogamous, pair-bonded primate species, but Wang, Moody, Newman, and Insel (1997) found that there were no sex differences in the distribution of immunoreactive oxytocin neurons and fibers in the common marmoset. Oxytocin immunoreactive neurons were found in the paraventricular and supraoptic nuclei of the hypothalamus, the bed nucleus of the stria teminalis, and the medial amygdala. Vasopressin cells were found in the paraventricular, supraoptic, and suprachiasmatic nuclei and in the lateral area of the hypothalamus. The only sex difference was that males had a greater density of vasopressin reactive cells in the bed nucleus of the stria terminalis than females. In a biparental species, in which both parents are essential for infant care and both sexes contribute to the formation and maintenance of a pair bond, it is reasonable to find no sex differences in distribution of oxytocin-reactive neurons in the brain.

In further work on common marmosets, Wang, Toloczko, et al. (1997) found vasopressin receptor binding in the nucleus accumbens, diagonal band, lateral septum, bed nucleus of the stria terminalis, amygdala, and anterodorsal and ventromedial hypothalamus, in addition to areas with immunoreactivity. Marmosets differed from voles in important ways: No vasopressin-producing cells were found in the amygdala. There was no plexus of immunoreactive fibers in the lateral septum. There was much greater visualization of vasopressin immunoreactive cells in the bed nucleus of the stria terminalis. Taken together, the results on marmosets suggest relatively little sexual dimorphism, an extensive overlap of oxytocin and vasopressin immunoreactive cells, and a different distribution than that found in rodents.

So far, pair formation and maintenance has been treated as a unitary, species-specific trait, and yet there may be considerable individual variation within species, as we have noted. Recently, Hammock and Young (2005) described variation in social engagement and affiliative behavior in monogamous male prairie voles and correlated this variation with a polymorphism in the promoter 
TABLE 3.2 Oxytocin and arginine vasopressin receptor distribution as a function of mating system in voles and monogamous common marmosets.

\begin{tabular}{|c|c|c|}
\hline Brain Area & $\begin{array}{l}\text { Monogamous vs. } \\
\text { Polygamous Vole }^{\mathrm{a}, \mathrm{b}}\end{array}$ & $\begin{array}{l}\text { Monogamous } \\
\text { Primate }^{c}\end{array}$ \\
\hline \multicolumn{3}{|l|}{ Oxytocin } \\
\hline Nucleus accumbens & Monogamous & NA \\
\hline Prelimbic cortex & Monogamous & NA \\
\hline Bed nucleus of stria terminalis & Monogamous & NA \\
\hline Midline thalamus & Monogamous & NA \\
\hline Ventral reunions & Monogamous & NA \\
\hline Lateral amygdala & Monogamous & NA \\
\hline Central amygdala & Both & NA \\
\hline Lateral septum & Polygamous & NA \\
\hline Ventromedial hypothalamus & Polygamous & NA \\
\hline \multicolumn{3}{|l|}{ Vasopressin } \\
\hline Diagonal band & Monogamous & Yes \\
\hline Laterodorsal thalamus & Monogamous & No \\
\hline Central amygdala & Monogamous & Yes \\
\hline Basolateral amygdala & Monogamous & Yes \\
\hline Bed nucleus stria terminalis & Monogamous & Yes \\
\hline Nucleus accumbens & Both & Yes \\
\hline Accessory olfactory bulb & Both & No \\
\hline Superior colliculus & Both & No \\
\hline Lateral septum & Polygamous & Yes \\
\hline Periventricular hypothalamus & NA & Yes \\
\hline Ventromedial hypothalamus & NA & Yes \\
\hline Suprachiasmatic hypothalamus & NA & Yes \\
\hline
\end{tabular}

axytocin data from "Oxytocin Receptor Distribution Reflects Social Organization in Monogamous and Polygamous Voles," by T. R. Insel and L. E. Shapiro, 1992, Proceedings of the National Academy of Sciences, USA, 89, pp. 5981-5985.

${ }^{b}$ Vasopressin data from Insel, Wang \& Ferris (1994).

'Marmoset vasopressin data from "Vasopressin in the Forebrain of Common Marmosets (Callithrix jacchus): Studies with in situ Hybridization, Immunocytochemistry and Receptor Autoradiography,' by Z. Wang, D. Toloczko, L. J. Young, K. Moody, J. D. Newman \& T. R. Insel, 1997, Brain Research, 768, pp. 147-156.

Note. $\mathrm{NA}=$ not reported or known

region of the vasopressin 1a receptor. Thus, variation in the promotor region of the receptor genes, and consequently the expression of vasopressin 1a receptors, may account for behavioral variation within a species. Similar studies remain to be done with respect to oxytocin receptors. The variation in receptor sensitivity to estrogen described by Champagne et al. (2001) as a function of early maternal licking and grooming suggests the possibility for an interaction between early experience and gene expression.

\section{SUMMARY}

We have demonstrated that both the proximate and ultimate mechanisms contributing to inter- and intraspecific variation across a wide range of cognitive phenomena can be best understood through a comparative lens that integrates not only phylogeny and brain size but also social and ecological factors. In our discussions of social learning, cooperation, spatial memory, and pair bonding, we have emphasized strong theoretical predictions about socioecological influences on the expression of these behaviors within and across taxa, and, when data have been available, we have highlighted underlying neuronal and hormonal differences that may relate to the observed variation.

One major implication of this comparative perspective is that no single species will likely serve as a suitable model for understanding the myriad of interesting human cognitive abilities. For example, there is strong momentum to use various species of macaques as model species for humans in neuroscience, but we should keep in mind the potential implications of the differing social and ecological pressures that macaque and human lineages have faced since the divergence of our ancestry nearly 40 million years ago. Awareness of the cognitive domains in which macaques and humans would be expected from a socioecological perspective to differ may sharpen interpretations of findings from macaque studies and generate interesting hypotheses about interspecific variation if we were to look beyond humans and macaques.

To better understand the selective pressures that have contributed to the wide range of expression of cognitive abilities across taxa, we must embrace data collected on primates and nonprimates alike and rely on multifaceted hypotheses that incorporate social and ecological pressures as well as phylogeny and brain size. Interdisciplinary collaboration is integral to accomplishing this feat but should yield a more comprehensive and generalizable understanding of both human and nonhuman cognition.

\section{REFERENCES}

Aiello, L., \& Dean, C. (1990). An introduction to human evolutionary anatomy. London: Academic Press.

Aisner, R., \& Terkel, J. (1992). Ontogeny of pine cone opening behaviour in the black rat Rattus rattus. Animal Behaviour, 44, 327-336.

Alexander, R. D. (1974). The evolution of social behavior. Annual Review of Ecology and Systematics, 5, 325-383.

Alger, S. J., \& Riters, L. V. (2006). Lesions to the medial preoptic nucleus differentially affect singing and nest box-directed behaviors within and outside of the breeding season in European starlings (Sturnus vulgaris). Behavioral Neuroscience, 120, 1326-1336. 


\section{Comparative Cognition and Neuroscience}

Axelrod, R., \& Hamilton, W. D. (1981, March 27). The evolution of cooperation. Science, 211, 1390-1396.

Balda, R. P., \& Kamil, A. C. (1992). Long-term spatial memory in Clark's nutcracker, Nucifraga columbiana. Animal Behaviour, 44, 761-769.

Barkley, C. L., \& Jacobs, L. F. (2007). Sex and species differences in spatial memory in food-storing kangaroo rats. Animal Behaviour, 73, 321-329.

Barrett, L., Henzi, P., \& Rendall, D. (2007). Social brains, simple minds: Does social complexity really require cognitive complexity? Philosophical Transactions of the Royal Society. Series B., 362, 561-575.

Bartecki, U., \& Heymann, E. W. (1987). Field observation of snakemobbing in a group of saddleback tamarins Saguinus fuscicollis nigrifrons. Folia Primatologica, 48, 199-202.

Bechara, A., Damasio, H., \& Damasio, A. R. (2000). Emotion, decision making and the orbitofrontal cortex. Cerebral Cortex, 10, 295-307.

Bednekoff, P. A., Balda, R. P., Kamil, A. C., \& Hile, A. G. (1997). Longterm spatial memory in four seed-caching corvid species. Animal Behaviour, 53, 335-341.

Bester-Meredith, J. K., \& Marler, C. A. (2001). Vasopressin and aggression in cross-fostered California mice (Peromyscus californicus) and white-footed mice (Peromyscus leucopus). Hormones and Behavior, 40, 51-64.

Bielsky, I. F., \& Young, L. J. (2004). Oxytocin, vasopressin and social recognition in mammals. Peptides, 25, 1565-1574.

Boesch, C., \& Boesch, H. (1989). Hunting behavior of wild chimpanzees in the Tai national park. American Journal of Physical Anthropology, 78, 547-573.

Bond, A. B., Kamil, A. C., \& Balda, R. P. (2007). Serial reversal learning and the evolution of behavioral flexibility in three species of North American corvids (Gymnorhinus cyanocephalus, Nucifraga columbiana, Aphelocoma californica). Journal of Comparative Psychology, 121, 372-379.

Box, H. O. (1984). Primate behavior and socioecology. London: Chapman \& Hall.

Boyd, R., \& Richerson, P. J. (1988). An evolutionary model of social learning: The effects of spatial and temporal variation. In T. R. Zentall \& B. G. Galef (Eds.), Social learning: Psychological and biological perspectives (pp. 29-48). Hillsdale, NJ: Erlbaum.

Brodin, A. (2005). Hippocampal volume does not correlate with foodhoarding rates in the black-capped chickadee (Poecile atricapillus) and willow tit (Parus montanus). Auk, 122, 819-828.

Brosnan, S. F., \& de Waal, F. B. M. (2002). A proximate perspective on reciprocal altruism. Human Nature, 13, 129-152.

Brown, J. L. (1983). Cooperation: A biologist's dilemma. Advances in the Study of Behavior, 13, 1-37.

Brown, J. L. (1987). Helping and communal breeding in birds: Ecology and evolution. Princeton, NJ: Princeton University Press.

Brownell, C. A., Ramani, G. B., \& Zerwas, S. (2006). Becoming a social partner with peers: Cooperation and social understanding in one- and two-year-olds. Child Development, 77, 803-821.

Burkart, J. M., Fehr, E., Efferson, C., \& van Schaik, C. P. (2007). Otherregarding preferences in a non-human primate: Common marmosets provision food altruistically. Proceedings of the National Academy of Sciences, USA, 104, 19762-19766.

Burton, J. J. (1977). Absence of spontaneous cooperative behavior in a troop of Macaca fuscata confronted with baited stones. Primates, 18, 359-366.

Byrne, R. W. (1994). The evolution of intelligence. In P. J. B. Slater \& T. R. Halliday (Eds.), Behavior and evolution (pp. 223-265). Cambridge, England: Cambridge University Press

Byrne, R. W. (1999). Imitation without intentionality: Using string parsing to copy the organization of behaviour. Animal Cognition, 2, 63-72.
Call, J., \& Tomasello, M. (1996). The effects of humans on the cognitive development of apes. In A. E. Russon, K. S. Bard, \& S. T. Parker (Eds.), Reaching into thought (pp. 371-403). Cambridge, England: Cambridge University Press.

Cambefort, J. P. (1981). A comparative study of culturally transmitted patterns of feeding habits in the chacma baboon (Papio ursinus) and the vervet monkey (Cercopithecus aethiops). Folia Primatologica, 36, 243-263.

Campbell, M. W., \& Snowdon, C. T. (2007). Vocal response of captivereared Saguinus oedipus during mobbing. International Journal of Primatology, 28, 257-270.

Campbell, M. W., \& Snowdon, C. T. (in press). Can captive-reared cottontop tamarins. Saguinus oedipus, learn to mob a predator? (in press). International Journal of Primatology.

Cardinal, R. N., Parkinson, J. A., Hall, J., \& Everitt, B. J. (2002). Emotion and motivation: The role of the amygdala, ventral striatum, and prefrontal cortex. Neuroscience and Biobehavioral Reviews, 26, 321-352.

Carter, C. S. (1998). Neuroendocrine perspectives on social attachment and love. Psychoneuroendocrinology, 23, 779-818.

Carter, C. S., DeVries, A. C., \& Getz, L. L. (1995). Physiological substrates of mammalian monogamy: The prairie vole model. Neuroscience and Biobehavioral Reviews, 19, 303-314.

Chalmeau, R. (1994). Do chimpanzees cooperate in a learning task? Primates, 35, 385-392.

Chalmeau, R., \& Gallo, A. (1996a). Cooperation in primates: Critical analysis of behavioural criteria. Behavioral Processes, 35, 101-111.

Chalmeau, R., \& Gallo, A. (1996b). What chimpanzees (Pan troglodytes) learn in a cooperative task. Primates, 37, 39-47.

Chalmeau, R., Lardeux, K., Brandibas, P., \& Gallo, A. (1997). Cooperative problem solving by orangutans (Pongo pygmaeus). International Journal of Primatology, 18, 23-32.

Chalmeau, R., Visalberghi, E., \& Gallo, A. (1997). Capuchin monkeys, Cebus apella, fail to understand a cooperative task. Animal Behaviour $54,1215-1225$.

Champagne, F., Diorio, J., Sharma, S., \& Meaney, M. J. (2001). Naturally occurring variations in maternal behavior in the rat are associated with differences in estrogen-inducible central oxytocin receptors. Proceedings of the National Academy of Sciences, USA, 98, 12736-12741.

Clayton, N. S. (1998). Memory and the hippocampus in food-storing birds: A comparative approach. Neuropharmacology, 37, 441-452.

Clayton, N. S., Yu, K. S., \& Dickinson, A. (2001). Scrub jays (Aphelocoma coerulescens) form integrated memories of the multiple features of caching episodes. Journal of Experimental Psychology: Animal Behavior Processes, 27, 17-29.

Coussi-Korbel, S., \& Fragaszy, D. M. (1995). On the relation between social dynamics and social learning. Animal Behaviour, 50, 1441-1453.

Creel, S., \& Creel, N. M. (1995). Communal hunting and pack size in African wild dogs, Lycaon pictus. Animal Behaviour, 50, 1325-1339.

Cronin, K. A., Kurian, A. V., \& Snowdon, C. T. (2005). Cooperative problem solving in a cooperatively breeding primate (Saguinus oedipus) Animal Behaviour, 69, 133-142.

Cronin, K. A., \& Snowdon, C. T. (2008). The effects of unequal reward distributions on cooperative performance by cottontop tamarins, Saguinus oedipus. Animal Behaviour, 75, 245-257.

Curio, E. (1978). The adaptive significance of avian mobbing: I Teleonomic hypotheses and predictions. Zeitschrift fur Tierpsychologie, $48,175-183$

Dantzer, R., Koob, G. F., Bluthé, R.-M., \& Le Moal, M. (1988). Septal vasopressin modulates social memory in rats. Brain Research, 457, 143-147.

de Waal, F. B. M., \& Luttrell, L. M. (1988). Mechanisms of social reciprocity in three primate species: Symmetrical relationship characteristics or cognition? Ethology and Sociobiology, 9, 101-118. 
di Pellegrino, G., Fadiga, L., Fogassi, L., Gallese, V., \& Rizzolatti, G. (1992). Understanding motor events: A neurophysiological study. Experimental Brain Research, 91, 176-180.

Dolman, C. S., Templeton, J., \& Lefebvre, L. (1996). Mode of foraging competition is related to tutor preference, Zenaida aurita. Journal of Comparative Psychology, 110, 45-54.

Dominey, W. J. (1983). Mobbing in colonially nesting fishes, especially the bluegill, Lepomis macrochirus. Copeia, 1086-1088.

Drea, C. M., \& Frank, L. G. (2003). The social complexity of spotted hyenas. In F. B. M. de Waal \& P. L. Tyack (Eds.), Animal social complex ity: Intelligence, culture, and individualized societies (pp. 121-148). Cambridge, MA: Harvard University Press.

Drea, C. M., \& Wallen, K. (1999). Low-status monkeys "play dumb" when learning in mixed social groups. Proceedings of the National Academy of Sciences, USA, 96, 12965-12969.

Dugatkin, L. A. (1997). Cooperation among animals: An evolutionary perspective. Oxford, England: Oxford University Press.

Dugatkin, L. A. (2002). Animal cooperation among unrelated individuals. Naturwissenschaften, 89, 533-541.

Dunbar, R. I. M. (1991). Functional significance of grooming in primates. Folia Primatologica, 57, 121-131.

Dunbar, R. I. M. (2003). The social brain: Mind, language, and society in evolutionary perspective. Annual Review of Anthropology, 32, 163-181.

DuVal, E. H. (2007). Social organization and variation in cooperative alliances among male lance-tailed manakins. Animal Behaviour, 73 , 391-401.

Fady, J. C. (1972). Absence of instrumental-type cooperation in feral Papio papio. Behaviour, 43, 157-164.

Ferguson, J. N., Aldag, J. M., Insel, T. R., \& Young, L. J. (2001). Oxytocin in the medial amygdala is essential for social recognition in the mouse. Journal of Neuroscience, 21, 8278-8285.

Fernandez-Duque, E., Mason, W. A., \& Mendoza, S. P. (1997). Effects of duration of separation on responses to mates and strangers in the monogamous titi monkey (Callicebus moloch). American Journal of Primatology, 43, 225-237.

Francis, D., Diorio, J., Liu, D., \& Meaney, M. J. (1999, November 5). Nongenomic transmission across generations of maternal behavior and stress responses in the rat. Science, 286, 1155-1158.

Frazier, C. R. M., Trainor, B. C., Cravens, C. J., Whitney, T. K., \& Marler, C.A. (2006). Paternal behavior influences development of aggression and vasopressin expression in male California mouse offspring. Hormones and Behaviour, 50, 699-707.

Friant, S. C., Campbell, M. A., \& Snowdon, C. T. (2008). Captive-born cotton-top tamarins (Saguinus oedipus) respond similarly to vocalizations of predators and non-predators. American Journal of Primatology, 70, 707-710

Galef, B. G., Jr., \& Allen, C. (1995). A new model system for studying behavioural traditions in animals. Animal Behaviour, 50, 705-715.

Galef, B. G., Jr., \& Laland, K. N. (2005). Social learning in animals Empirical studies and theoretical models. BioScience, 55, 489-499.

Gallese, V., Fadiga, L., Fogassi, L., \& Rizzolatti, G. (1996). Action recognition in the premotor cortex. Brain, 119, 593-609.

Gaulin, S. J. C., \& Fitzgerald, R. W. (1989). Sexual selection for spatial learning ability. Animal Behaviour, 37, 322-331

Gilby, I. C., Eberly, L. E., \& Wrangham, W. R. (2008). Economic profitability of social predation among wild chimpanzees: Individual variation promotes cooperation. Animal Behaviour, 75, 351-360.

Gimpl, G., \& Fahrenholz, F. (2001). The oxytocin receptor system: Structure, function, and regulation. Physiological Reviews, 81, 629-683.

Gonzaga, G. C., Turner, R. A., Keltner, D., Campos, B., \& Altemus, M. (2006). Romantic love and sexual desire in close relationships. Emotion, 6, 163-179.
Goodall, J. (1986). The chimpanzees of Gombe: Patterns of behavior. Cambridge, MA: Belknap Press.

Grewen, K. M., Girdler, S. S., Amico, J., \& Light, K. C. (2005). Effects of partner support on resting oxytocin, cortisol, norepinephrine, and blood pressure before and after warm partner contact. Psychosomatic Medicine, 67, 531-538

Gubernick, D. J., \& Tefari, T. (2000). Adaptive significance of male parental care in a monogamous mammal. Proceedings of the Royal Society of London. Series B, 267, 147-150.

Hamilton, W. D. (1963). The evolution of altruistic behavior. American Naturalist, 97, 354-356.

Hamilton, W. D. (1964). The genetical evolution of social behavior. Journal of Theoretical Biology, 7, 1-52.

Hammerstein, P. (2003). Why is reciprocity so rare in social animals? A protestant appeal. In P. Hammerstein (Ed.), The genetic and cultural evolution of cooperation (pp. 83-93). Cambridge, MA: MIT Press.

Hammock, E. A. D., \& Young, L. J. (2005, June 10). Microsatellite instability generates diversity in brain and sociobehavioral traits. Science, 308, 1630-1634.

Hampton, R. R., \& Shettleworth, S. J. (1996). Hippocampus and memory in food-storing and in a nonstoring bird species. Behavioral Neuroscience, 110, 946-964.

Harbaugh, W. T., Mayr, U., \& Burghart, D. R. (2007, June 15). Neural responses to taxation and voluntary giving reveal motives for charitable donations. Science, 316, 1622-1625.

Hare, B., Melis, A. P., Woods, V., Hastings, S., \& Wrangham, R. (2007). Tolerance allows bonobos to outperform chimpanzees on a cooperative task. Current Biology, 17, 619-623.

Hare, B., \& Tomasello, M. (2004). Chimpanzees are more skilful in competitive than in cooperative cognitive tasks. Animal Behaviour, 68, 571-581.

Hart, B. L., \& Hart, L. A. (1992). Reciprocal allogrooming in impala, Aepyceros melampus. Animal Behaviour, 44, 1073-1083.

Hasler, A. D. (1966). Underwater guideposts: The homing of salmon. Madison: University of Wisconsin Press.

Hauser, M. D., Chen, K. M., Chen, F., \& Chuang, E. (2003). Give unto others: Genetically unrelated cotton-top tamarin monkeys preferentially give food to those who altruistically give food back. Proceedings of the Royal Society of London. Series B, 270, 2363-2370.

Hauser, M. D., Newport, E. L., \& Aslin, R. N. (2001). Statistical learning of the speech stream in a non-human primate: Statistical learning in cotton-top tamarins. Cognition, 78, B53-B64.

Hayes, S. L., \& Snowdon, C. T. (1990). Predator recognition in cotton-top tamarins (Saguinus oedipus). American Journal of Primatology, 20, 283-291.

Hennessy, D. F., \& Owings, D. H. (1978). Snake species discrimination and the role of olfactory cues in the snake-directed behavior of the California ground squirrel. Behaviour, 65, 115-124.

Hodos, W., \& Campbell, C. B. G. (1969). Scala naturae: Why there is no theory in comparative psychology. Psychological Review, 76, 337-350.

Hollander, E., Bartz, J., Chaplin, W., Phillips, A., Sumner, J., Soorya, L. et al. (2006). Oxytocin increases retention of social cognition. Biological Psychiatry, 61, 498-503.

Hollander, E., Novatny, S., Hanratty, N., Yaffe, R., deCaria, C., Aronowitz, B. R., et al. (2003). Oxytocin infusion reduces repetitive behaviors in adults with autism and Asperger's disorders. Neuropsychopharmacology, 28, 193-198.

Hoogland, J. L., \& Sherman, P. W. (1976). Advantages and disadvantages of bank swallow coloniality. Ecological Monographs, 46, 33-58.

Horner, V., \& Whiten, A. (2005). Causal knowledge and imitation/emulation switching in chimpanzees (Pan troglodytes) and children (Homo sapiens). Animal Cognition, 8, 164-181. 


\section{Comparative Cognition and Neuroscience}

Humle, T., \& Snowdon, C. T. (2008). Socially biased learning in the acquisition of a complex foraging task in juvenile cottontop tamarins, Saguinus oedipus. Animal Behaviour, 75, 267-277.

Ichihara-Takeda, S., \& Funahashi, S. (2006). Reward-period activity in primate dorsolateral prefrontal and orbitofrontal neurons is affected by reward schedules. Journal of Cognitive Neuroscience, 18, 212-226.

Inoue-Nakamura, N., \& Matsuzawa, T. (1997). Development of stone tool use by wild chimpanzees (Pan troglodytes). Journal of Comparative Psychology, 111, 159-173.

Insel, T. R. (2003). Is social attachment an addictive disorder? Physiology and Behavior, 79, 351-357.

Insel, T. R., \& Hulihan, T. J. (1995). A gender-specific mechanism for pair bonding: Oxytocin and partner preference formation in monogamous voles. Behavioral Neuroscience, 109, 782-789.

Insel, T. R., \& Shapiro, L. E. (1992). Oxytocin receptor distribution reflects social organization in monogamous and polygamous voles. Proceedings of the National Academy of Sciences, USA, 89, 5981-5985.

Insel, T. R., Wang, Z.-X., \& Ferris, C. F. (1994). Patterns of brain vasopressin receptor distribution associated with social organization in microtine rodents. Journal of Neuroscience, 14, 5381-5392.

Jacobs, L. F., Gaulin, S. J. C., Sherry, D. G., \& Hoffman, G. E. (1990). Evolution of spatial cognition: Sex specific patterns of spatial behavior predict hippocampal size. Proceedings of the National Academy of Sciences, USA, 87, 6349-6352.

Jensen, K., Hare, B., Call, J., \& Tomasello, M. (2006). What's in it for me? Self-regard precludes altruism and spite in chimpanzees. Proceedings of the Royal Society of London. Series B, 273, 1013-1021.

Johnston, T. D. (1982). The selective costs and benefits of learning: An evolutionary analysis. Advances in the Study of Behavior, 12, 65-106.

Jouventin, P., Pasteur, G., \& Cambefort, J. P. (1976). Observational learning of baboons and avoidance of mimics: Exploratory tests. Evolution, $31,214-218$.

Kawai, M. (1965). Newly acquired pre-cultural behavior of the natural troop of Japanese monkeys on Koshima Islet. Primates, 6, 1-30.

Keysers, C., Kohler, E., Umiltà, M. A., Nanetti, L., Fogassi, L., \& Gallese, V. (2003). Audiovisual mirror neurons and action recognition. Experimental Brain Research, 153, 628-636.

King-Casas, B., Tomlin, D., Anen, C., Camerer, C. F., Quartz, S. R., \& Montague, P. R. (2005, April 1). Getting to know you: Reputation and trust in a two-person economic exchange. Science, 308, 78-83.

Klopfer, P. H. (1959). Social interactions in discrimination learning with special reference to feeding behavior in birds. Behaviour, 14, 282-299.

Klopfer, P. H. (1961). Observational learning in birds: The establishment of behavioral modes. Behaviour, 17, 71-80.

Kohler,E., Keysers,C.,Umiltà,M.A.,Fogassi,L., Gallese, V.,\&Rizzolatti, G. (2002, August 2). Hearing sounds, understanding actions: Action representation in mirror neurons. Science, 297, 846

Kosfeld, M., Heinrichs, M., Zak, P. J., Fischbacher, U., \& Fehr, E. (2005, June 2). Oxytocin increases trust in humans. Nature, 435, 673-676.

Laland, K. N. (2004). Social learning strategies. Learning and Behavior, 32, 4-14.

Lazaro-Perea, C., de Fatima Arruda, M., \& Snowdon, C. T. (2004) Grooming as a reward? Social function of grooming between females in cooperatively breeding marmosets. Animal Behaviour, 67, 627-636.

Leavens, D. A., Hopkins, W. D., \& Bard, K. A. (2005). Understanding the point of chimpanzee pointing: Epigenesis and ecological validity. Current Directions in Psychological Science, 14, 185-189.

Lefebvre, L., \& Palameta, B. (1988). Mechanisms, ecology, and population diffusion of socially learned, food-finding behavior in feral pigeons. In T. R. Zentall \& B. G. Galef, Jr. (Eds.), Social learning: Psychological and biological perspectives (pp. 141-164). Hillsdale, NJ: Erlbaum.
Levy, F., Kendrick, K. M., Goode, J. A., Guevara-Guzman, R., \& Keverne, E. B. (1995). Oxytocin and vasopressin release in the olfactory bulb of parturient ewes: Changes with maternal experience and effects on acetylcholine, gamma-aminobutyric acid, glutamate and noradrenaline release. Brain Research, 669, 197-206.

Liu, D., Diorio, J., Day, J. C., Francis, D. D., \& Meaney, M. J. (2000) Maternal care hippocampal synaptogenesis and cognitive development in rats. Nature Neuroscience, 3, 799-806.

Liu, D., Diorio, J., Tannenbaum, B., Caldji, C., Francis, D., Freedman, A., et al. (1997, September 12). Maternal care hippocampal glucocorticoid receptors and hypothalamic-pituitary-adrenal responses to stress. Science, 277, 1659-1662.

Lonsdorf, A. V., Eberly, L. E., \& Pusey, A. E. (2004, April 15). Sex differences in learning in chimpanzees. Nature, 428, 715-716.

Lupfer, G., Frieman, J., \& Coonfield, D. (2003). Social transmission of flavor preferences in two species of hamsters (Mesocricetus auratus and Phodopus campbelli). Journal of Comparative Psychology, 117, 449-455.

Marler, C. A., Bester-Meredith, J. K., \& Trainor, B. C. (2003). Paterna behavior and aggression: Endocrine mechanisms and non-genomic transmission of behavior. Advances in the Study of Behavior, 32, 263-323.

Matsuzawa, T. (Ed.). (2001). Primate origins of human cognition and behavior. Tokyo: Springer-Verlag.

Mayr, E. (1961, November 10). Cause and effect in biology. Science, 134, 1501-1506.

McCabe, K., Houser, D., Ryan, L., Smith, V., \& Trouard, T. (2001). A functional imaging study of cooperation in two-person reciprocal exchange. Proceedings of the National Academy of Sciences, USA, 98, 11832-11835.

Melis, A. P., Hare, B., \& Tomasello, M. (2006). Engineering cooperation in chimpanzees: Tolerance constraints on cooperation. Animal Behaviour, 72, 275-286.

Mendoza, S. P., \& Mason, W. A. (1986a). Contrasting response to intruders and involuntary separation by monogamous and polygamous New World monkeys. Physiology and Behavior, 38, 795-801.

Mendoza, S. P., \& Mason, W. A. (1986b). Parental division of labor and differentiation of attachments in a monogamous primate (Callicebus moloch). Animal Behaviour, 34, 1336-1347.

Mendres, K. A., \& de Waal, F. B. M. (2000). Capuchins do cooperate: The advantage of an intuitive task. Animal Behaviour, 60, 523-529.

Miklosi, A. (1999). The ethological analysis of imitation. Biological Reviews, 74, 347-374.

Milinski, M. (1987, January 29). Tit for tat in sticklebacks and the evolution of cooperation. Nature, 325, 433-435.

Nelson, E. E., \& Panksepp, J. (1998). Brain substrates of infant-mother attachment: Contributions of opioids, oxytocin, and norepinephrine. Neuroscience and Biobehavioral Reviews, 22, 437-452.

Nicol, C. J., \& Pope, S. J. (1994). Social learning in small flocks of laying hens. Animal Behaviour, 47, 1289-1296.

Nottebohm, F. (1981, December 18). A brain for all seasons: Cyclical anatomic changes in song control nuclei of the canary brain. Science, 214 1368-1370.

Nowak, R. M. (1999). Walker's primates of the world. Baltimore: Johns Hopkins University Press.

Owren, M. J., \& Rendall, D. (1997). An affect-conditioning model of nonhuman primate vocal signaling. In M. D. Beecher, D. H. Owings, \& N. S. Thompson (Eds.), Perspectives in ethology (Vol. 12, pp. 399346). New York: Plenum Press.

Packer, C., \& Ruttan, L. (1988). The evolution of cooperative hunting. American Naturalist, 132, 159-198.

Padoa-Schioppa, C., \& Assad, J. A. (2006, May 11). Neurons in the orbitofrontal cortex encode economic value. Nature, 441, 223-226. 
Pedersen, C. A., \& Boccia, M. L. (2002). Oxytocin maintains as well as initiates female sexual behavior: Effects of a highly selective oxytocin antagonist. Hormones and Behavior, 41, 170-177.

Petit, O., Desportes, C., \& Thierry, B. (1992). Differential probability of "coproduction" in two species of macaque (Macaca tonkeana, M. mulatta). Ethology, 90, 107-120.

Pfeiffer, T., Rutte, C., Killingback, T., Taborsky, M., \& Bonhoeffer, S. (2005) Evolution of cooperation by generalized reciprocity. Proceedings of the Royal Society of London. Series B, 272, 1115-1120.

Popik, P., \& van Ree, J. M. (1991). Oxytocin but not vasopressin facilitates social recognition following injection into the medial preoptic area of the rat brain. European Neuropsychopharmacology, 1, 555-560.

Pravosudov, V. V., \& Clayton, N. S. (2002). A test of the adaptive specialization hypothesis: Population differences in caching memory and the hippocampus in black-capped chickadee (Poecile atricapilla). Behavioral Neuroscience, 116, 515-522.

Pravosudov, V. V., \& de Kort, S. R. (2006). Is the Western scrub-jay (Aphelocoma californica) really an underdog among food-caching corvids when it comes to hippocampal volume and food caching propensity? Brain, Behavior and Evolution, 67, 1-9.

Premack, D. G., \& Woodruff, G. (1978). Does the chimpanzee have a theory of mind? Behavioral and Brain Sciences, 1, 515-526.

Ribble, D. O. (1991). The monogamous mating system of Peromyscus californicus as revealed by DNA fingerprinting. Behavioral Ecology and Sociobiology, 29, 161-166.

Rilling, J. K., Glenn, A. L., Jairam, M. R., Pagnoni, G., Goldsmith, D. R., Elfenbein, H. A., et al. (2007). Neural correlates of social cooperation and non-cooperation as a function of psychopathy. Biological Psychiatry, 61, 1260-1271.

Rilling, J. K., Gutman, D. A., Zeh, T. R., Pagnoni, G., Berns, G. S., \& Kilts, C. D. (2002). A neural basis for social cooperation. Neuron, 35, 395-405.

Rilling, J. K., Sanfey, A. G., Aronson, J. A., Nystrom, L. E., \& Cohen, J. D. (2004). Opposing bold responses to reciprocated and unreciprocated altruism in putative reward pathways. NeuroReport, 15, 2539-2543.

Rizzolatti, G., \& Craighero, L. (2004). The mirror-neuron system. Annual Review of Neuroscience, 27, 169-192.

Rizzolatti, G., Fadiga, L., Gallese, V., \& Fogassi, L. (1996). Premotor cortex and the recognition of motor actions. Cognitive Brain Research, 3, 131-141.

Rizzolatti, G., Fogassi, L., \& Gallese, V. (2001). Neurophysiological mechanisms underlying the understanding of imitation and action. Nature Reviews Neuroscience, 2, 661-670.

Roesch, M. R., \& Olson, C. R. (2004, April 9). Neuronal activity related to reward value and motivation in primate frontal cortex. Science, 304 307-310.

Rosenblum, L. A., Smith, E. L. P., Altemus, M., Scharf, B. A., Owens, M. J., Nemeroff, C. B., et al. (2002). Differing concentrations of corticotrophin releasing factor and oxytocin in the cerebrospinal fluid of bonnet and pigtail macaques. Psychoneuroendocrinology, 27, 651-660.

Rukstalis, M., \& French, J. A. (2005). Vocal buffering of the stress response: Exposure to conspecific vocalizations moderates urinary cortisol excretion in isolated marmosets. Hormones and Behavior, 47, 1-7.

Rutte, C., \& Taborsky, M. (2007). Generalized reciprocity in rats. Public Library of Science, 5, 1421-1425.

Rutte, C., \& Taborsky, M. (2008). The influence of social experience on cooperative behaviour of rats (Rattus norvegicus): Direct vs. generalised reciprocity. Behavioral Ecology and Sociobiology, 62, 499-505.

Rypstra, A. L., \& Tirey, R. S. (1991). Prey size, prey perishability and group foraging in a social spider. Oecologia, 86, 25-30.

Saffran, J. R., Aslin, R. N., \& Newport, E. L. (1996, December 13) Statistical leaning in 8-month-old infants. Science, 274, 1926-1928.
Savage, A., Ziegler, T. E., \& Snowdon, C. T. (1988). Sociosexual development, pair bond formation and mechanisms of fertility suppression in female cotton-top tamarins (Saguinus oedipus oedipus). American Journal of Primatology, 14, 345-359.

Schaffner, C. M., Shepherd, R. E., Santos, C. V., \& French, J. A. (1995) Development of heterosexual relationship in Wied's black tufted-ear marmosets (Callithrix kuhli). American Journal of Primatology, 36 , 185-200.

Schaller, G. B. (1972). The Serengeti lion. Chicago: University of Chicago Press.

Scheel, D., \& Packer, C. (1991). Group hunting behaviour of lions: A search for cooperation. Animal Behaviour, 41, 697-709.

Schultz, W., Dayan, P., \& Montague, P. R. (1997, March 14). A neural substrate of prediction and reward. Science, 275, 1593-1599.

Schuster, R. (2002). Cooperative coordination as a social behavior. Human Nature, 13, 47-83.

Schuster, R., \& Perelberg, A. (2004). Why cooperate? An economic perspective is not enough. Behavioural Processes, 66, 261-277.

Schwab, C., Bugnyar, T., Schloegl, C., \& Kotrschal, K. (2008). Enhanced social learning between siblings in common ravens, Corvus corax. Animal Behaviour, 75, 501-508.

Sherry, D. F., Jacobs, L. F., \& Gaulin, S. J. C. (1992). Spatial memory and adaptive specialization of the hippocampus. Trends in Neuroscience, $15,298-303$.

Shields, W. M. (1984). Barn swallow mobbing: Self defence, collateral defence, group defence or paternal care? Animal Behaviour, 32 132-148.

Silk, J. B., Brosnan, S. F., Vonk, J., Henrich, J., Povinelli, D. J., Richardson, A. S., et al. (2005, October 27). Chimpanzees are indifferent to the welfare of unrelated group members. Nature, 437, 1357-1359.

Silva, H. P. A., \& Sousa, M. B. C. (1997). The pair-bond formation and its role in the stimulation of reproductive function in female common marmosets (Callithrix jacchus). International Journal of Primatology, $18,387-400$.

Smith, G. T., Brenowitz, E. A., Beecher, M. D., \& Wingfield, J. C. (1997) Seasonal changes in testosterone, neural attributes of song control nuclei, and song structure in wild songbird. Journal of Neuroscience, 17, 6001-6010.

Smith, T. E., \& French, J. A. (1997). Social and reproductive condition modulate urinary cortisol excretion in black tufted-ear marmosets (Callithrix kuhli). American Journal of Primatology, 42, 253-267.

Snowdon, C. T., \& Boe, C. Y. (2003). Social communication about unpalatable foods in tamarins (Saguinus oedipus). Journal of Comparative Psychology, 117, 142-148.

Snowdon, C. T., \& Cronin, K. A. (2007). Cooperative breeders do cooperate. Behavioural Processes, 76, 138-141.

Snowdon, C. T., \& Ziegler, T. E. (2007). Growing up cooperatively. Journal of Developmental Processes, 2, 40-66.

Solomon, N. G., \& French, J. A. (1997). Cooperative breeding in mammals. Cambridge, England: Cambridge University Press.

Spence, K. W. (1937). Experimental studies of learning and the higher mental processes in infra-human primates. Psychological Bulletin, 34 806-850.

Stander, P. E. (1992). Cooperative hunting in lions: The role of the individual. Behavioral Ecology and Sociobiology, 29, 445-454.

Stevens, J. R., \& Hauser, M. D. (2004). Why be nice? Psychological constraints on the evolution of cooperation. Trends in Cognitive Sciences, $8,60-65$.

Strier, K. B. (1997). Subtle cues of social relationships in male muriqui monkeys (Brachyteles arachnoides). In W. G. Kinzey (Ed.), New world primates: Evolution ecology and behavior (pp. 109-118). New York: Aldine de Gruyter. 


\section{Comparative Cognition and Neuroscience}

Tebbich, S., Taborsky, M., \& Winkler, H. (1996). Social manipulation causes cooperation in keas. Animal Behaviour, 52, 1-10.

Templeton, J. J., Kamil, A. C., \& Balda, R. P. (1999). Sociality and social learning in two species of corvids: The pinyon jay (Gymnorhinus cyanocephalus) and the Clark's nutcracker (Nucifraga columbiana). Journal of Comparative Psychology, 113, 450-455.

Thompson, R. K. R., Oden, D. L., \& Boysen, S. T. (1997). Languagenaive chimpanzees (Pan troglodytes) judge relations between relations in a conceptual matching-to-sample task. Journal of Experimental Psychology: Animal Behavior Processes, 23, 31-43.

Thornton, A., \& McAuliffe, K. (2006, July 14). Teaching in wild meerkats. Science, 313, 227-229.

Tooby, J., \& Cosmides, L. (1990). The past explains the present: Emotional adaptations and the structure of ancient environments. Ethology and Sociobiology, 11, 375-424.

Trivers, R. L. (1971). The evolution of reciprocal altruism. Quarterly Review of Biology, 46, 35-57.

Turner, R. A., Altemus, M., Enos, T., Cooper, B., \& McGuinness, T. (1999). Preliminary research on plasma oxytocin in normally-cycling women: Investigating emotion and interpersonal distress. Psychiatry, 62, 97-113.

Umiltà, M. A., Kohler, E., Gallese, V., Fogassi, L., Fadiga, L., Keysers, C., et al. (2001). I know what you are doing: A neurophysiological study. Neuron, 31, 155-165.

Uvnas-Moberg, K. (1998). Oxytocin may mediate the benefits of positive social interactions and emotions. Psychoneuroendocrinology, 23, 819-835.

van Schaik, C. P., \& Kappeler, P. M. (2006). Cooperation in primates and humans: Closing the gap. In P. M. Kappeler \& C. P. van Schaik (Eds.), Cooperation in primates and humans: Mechanisms and evolution (pp. 3-21). Berlin, Germany: Springer-Verlag.

Visalberghi, E. (1997). Success and understanding in cognitive tasks A comparison between (Cebus apella) and (Pan troglodytes). International Journal of Primatology, 18, 811-830.

Visalberghi, E., Pellegrini Quarantotti, B., \& Tranchida, F. (2000). Solving a cooperation task without taking into account the partner's behavior: The case of capuchin monkeys (Cebus apella). Journal of Comparative Psychology, 114, 297-301.

Von Frisch, K. (1950). Bees: Their vision, chemical senses and language Ithaca, NY: Cornell University Press.

Vonk, J., Brosnan, S. F., Silk, J. B., Henrich, J., Richardson, A. S. Lambeth, S. P., et al. (2008). Chimpanzees do not take advantage of very low cost opportunities to deliver food to unrelated group members. Animal Behaviour, 75, 1757-1770.

Vonk, J., \& Povinelli, D. J. (2006). Similarity and difference in the conceptual system of primates: The unobservability hypothesis. In E. Wasserman \& T. Zentall (Eds.), Comparative cognition: Experimental explorations of animal intelligence (pp. 363-387). Oxford, England: Oxford University Press.
Wang, Z., Moody, K., Newman, J. D., \& Insel, T. R. (1997). Vasopressin and oxytocin immunoreactive neurons and fibers in the forebrain of male and female common marmosets (Callithrix jacchus). Synapse, 27, 14-25.

Wang, Z., Toloczko, D., Young, L. J., Moody, K., Newman, J. D., \& Insel, T. R. (1997). Vasopressin in the forebrain of common marmosets (Callithrix jacchus): Studies with in situ hybridization, immunocytochemistry and receptor autoradiography. Brain Research, 768, 147-156.

Werdenich, D., \& Huber, L. (2002). Social factors determine cooperation in marmosets. Animal Behaviour, 64, 771-781.

West, S. A., Griffin, A. S., \& Gardner, A. (2007). Social semantics: Altruism, cooperation, mutualism, strong reciprocity and group selection. Journal of Evolutionary Biology, 20, 415-432.

Whiten, A., \& Ham, R. (1992). On the nature and evolution of imitation in the animal kingdom: Reappraisal of a century of research. Advances in the Study of Behavior, 21, 239-283.

Whiten, A., Horner, V., \& Litchfield, C. A. (2004). How do apes ape? Learning and Behavior, 32, 36-52.

Widowski, T. M., Porter, T. A., Ziegler, T. E., \& Snowdon, C. T. (1992). The stimulatory effect of males on the initiation, but not the maintenance, of ovarian cycling in cotton-top tamarins (Saguinus oedipus). American Journal of Primatology, 26, 97-108.

Wilkinson, G. S. (1984, March 8). Reciprocal food sharing in the vampire bat. Nature, $308,181-184$

Williams, J. R., Catania, K. C., \& Carter, C. S. (1992). Development of partner preferences in female prairie voles (Microtus ochrogaster): The role of social and sexual experience. Hormones and Behavior, 26, 339-349.

Winslow, J. T., Hastings, N., Carter, C. S., Harbaugh, C. R., \& Insel, T. R. (1993, October 7). A role for central vasopressin in pairbonding in monogamous prairie voles. Nature, 365, 545-548.

Winslow, J. T., Noble, P. L., Lyons, C. K., Sterk, S. M., \& Insel, T. S. (2003). Rearing effects on cerebrospinal fluid oxytocin concentration and social buffering in rhesus monkeys. Neuropsychopharamacology, 28, 910-918.

Wismer Fries, A. B., Ziegler, T. E., Kurian, J. R., Jacoris, S., \& Pollak, S. D. (2005). Early experience in humans is associated with changes in neuropeptides critical for regulating social behavior. Proceedings of the National Academy of Sciences, USA, 102, 17237-17240.

Witt, D. M., Winslow, J. T., \& Insel, T. R. (1992). Enhanced social interactions in rats following chronic, centrally infused oxytocin. Pharmacology, Biochemistry, and Behavior, 43, 855-861.

Young, L. J. (1999). Oxytocin and vasopressin receptors and speciestypical social behaviors. Hormones and Behavior, 36, 212-221.

Young, L. J., \& Wang, Z. (2004). The neurobiology of pair bonding. Nature Neuroscience, 7, 1048-1054.

Zak, P. J., Kurzban, R., \& Matzner, W. T. (2005). Oxytocin is associated with human trustworthiness. Hormones and Behaviour, 48, 522-527.

Zak, P. J., Stanton, A. A., \& Ahmadi, S. (2007). Oxytocin increases generosity in humans. Public Library of Science, 2(11), E1128. 